\title{
A Systematic Review of PCSK9 Inhibitors Alirocumab and Evolocumab
}

\author{
Marian McDonagh, PharmD; Kim Peterson, MS; \\ Brittany Holzhammer, MPH; and Sergio Fazio, MD, PhD
}

\begin{abstract}
BACKGROUND: The proprotein convertase subtilisin/kexin type 9 (PCSK9) inhibitors are a new class of cholesterol-lowering medications that provide significant reductions in lipids but at a large cost relative to statins. With 2 such drugs now on the market, alirocumab and evolocumab, comparing the evidence base for these drugs is necessary for informed decision making.
\end{abstract}

OBJECTIVE: To compare the benefits and harms of the PCSK9 inhibitors alirocumab and evolocumab.

METHODS: The databases Ovid MEDLINE, Cochrane Library, SCOPUS, and ClinicalTrials.gov were used to search for randomized controlled trials of alirocumab or evolocumab with any relevant comparator reporting health outcomes, lipid outcomes, or harms through September 2015, and information was requested from manufacturers. Results were reviewed according to standard review methods.

RESULTS: The database searches revealed 17 fair- and good-quality trials; however, none had primary health outcomes or directly compared PCSK9 inhibitors. Alirocumab (75 mg to $150 \mathrm{mg}$ subcutaneously every 2 weeks) resulted in significantly greater reductions in low-density lipoprotein cholesterol (LDL-C; $-8 \%$ to $-67 \%$ ) at $12-24$ weeks in patients with (a) heterozygous familial hypercholesterolemia and (b) patients at high or varied cardiovascular (CV) risk who were not at LDL-C goals with statin therapy. The highest strength evidence was for patients with high CV risk not at LDL-C goals. Alirocumab also resulted in high-density lipoprotein cholesterol (HDL-C) increases of 6\%-12\%. Low- and moderate-strength evidence for adjudicated CV events at 52-78 weeks for a priori analyses indicated no benefit. Low- and moderate-strength evidence also found no differences in harms except possibly slightly more injection-site reactions. Evolocumab (120 mg subcutaneously every 2 weeks to $420 \mathrm{mg}$ every 4 weeks) resulted in significantly greater reductions in LDL-C (-32\% to $-71 \%)$ at $12-52$ weeks in patients with heterozygous or homozygous familial hypercholesterolemia, patients intolerant of statins, and patients with varied CV risk not at LDL-C goal with statin therapy. The highest strength evidence was for heterozygous familial hypercholesterolemia and patients not at LDL-C goals. Moderate-strength evidence showed HDL-C increases in the range of $4.5 \%-6.8 \%$. Harms were not different between groups, except possibly slightly greater overall adverse event reporting. Evidence on adjudicated CV outcomes was insufficient to draw conclusions because of sparseness of events, study limitations, and inability to assess consistency of findings.

CONCLUSIONS: Alirocumab and evolocumab have evidence of large improvements in lipid levels. The strength of the evidence is greater for alirocumab than evolocumab in patients with high CV risk who were not at LDL-C target goals, while evidence for evolocumab is stronger in patients with heterogeneous familial hypercholesterolemia and patients with varied CV risk who were not at LDL-C target goals. Evidence on adjudicated CV outcomes for a priori analyses is unable to show benefit for alirocumab and is insufficient to draw conclusions for evolocumab. Important questions remain about the comparative effects on long-term health outcomes.

J Manag Care Spec Pharm. 2016;22(6):641-53

Copyright $\odot 2016$, Academy of Managed Care Pharmacy. All rights reserved.

\section{What is already known about this subject}

The proprotein convertase subtilisin/kexin type 9 (PCSK9) inhibitors alirocumab and evolocumab produce large reductions in low-density lipoprotein cholesterol (LDL-C) when given in addition to statins in a variety of populations with hypercholesterolemia or alone or in combination with ezetimibe in patients intolerant to statins.

Cardiovascular benefits are as yet not clearly established, with some analyses of incidentally reported or secondary outcomes indicating benefit.

Concerns raised about the evidence include the methodology behind cardiovascular endpoint analyses, long-term effects of large reductions in lipids, whether comparison groups were optimal, and cost of the drugs in light of these concerns.

\section{What this study adds}

This study compared the strength of the evidence base for each of the PCSK9 inhibitors alirocumab and evolocumab.

The evidence base for alirocumab is stronger than evolocumab for patients at high cardiovascular risk who have not reached LDL-C targets with statin therapy. Although there is strong evidence that alirocumab lowers lipids significantly, there is currently no evidence of a benefit in cardiovascular outcomes when limiting to adjudicated cardiovascular events and a priori analyses.

Evidence for evolocumab is stronger than alirocumab for patients with heterogeneous familial hypercholesterolemia and patients with varied cardiovascular risk not at LDL-C target, but evidence on cardiovascular events is insufficient or absent. Evolocumab also has evidence in these other populations: homozygous familial hypercholesterolemia, populations of patients with varied cardiovascular risk, and follow-up studies of varied populations.

T] MG-CoA reductase inhibitors, or statins, have been the primary therapeutic intervention for hypercholesterolemia for decades. They have been successful in reducing the risk of major cardiovascular events and mortality in a wide range of at-risk individuals. ${ }^{1,2}$ However, there are patients for whom statins alone or in combination with other lipid-lowering therapies are not always adequate to reduce cardiovascular risk, even at maximally tolerated doses. There are also patients who are intolerant of statin therapy, in whom treatment with 
drugs such as ezetimibe alone are also inadequate. Monoclonal antibodies that inhibit proprotein convertase subtilisin/kexin type 9 (PCSK9) have been under development as novel therapies, potentially filling these gaps in current standard therapies for hypercholesterolemia. The first 2 drugs in this new class of antihyperlipidemic treatments received U.S. Food and Drug Administration (FDA) approval in mid-2015. In combination with other treatments-typically maximally tolerated statinsalirocumab was approved for use in heterozygous familial hypercholesterolemia or clinical atherosclerotic cardiovascular disease who required additional low-density lipoprotein cholesterol (LDL-C) lowering, and evolocumab was approved for patients with clinical atherosclerotic cardiovascular disease or heterozygous and homozygous familial hypercholesterolemia who required additional LDL-C lowering.

Alirocumab (Praluent) and evolocumab (Repatha) have shown striking LDL-C reductions over 10 to 78 weeks (26\%$67 \%$ ). But, as with many novel specialty drugs, the promise of better results with PCSK9 inhibitors comes with a high price tag-in this case, the cost is estimated at more than $\$ 14,000$ per patient per year. ${ }^{3-5}$ In this cost-conscious era of health care, clinicians, payers, and the public are already questioning how to best manage this costly new drug class. ${ }^{6}$ While there have been reviews of the evidence published, ${ }^{7,8}$ there has been concerning criticism of the analysis of the evidence, as well as the evidence itself. These concerns center around long-term health outcomes (including handling of data in meta-analyses) $)^{9,10}$ and comparison groups in trials (e.g., high-intensity statins). ${ }^{11-14}$

To date, no clinical trial of a PCSK9 inhibitor designed a priori, with adequate size and duration, to assess cardiovascular outcomes as the primary outcomes has yet been completed. However, 4 such trials are underway and are expected to be completed in 2018..$^{15-18}$ In the meantime, Navarese et al. (2015) pooled data from the 24 available smaller studies with follow-up ranging from 2 months to 2 years and reported that PCSK9 inhibitors as a group reduce all-cause mortality (odds ratio $[\mathrm{OR}]=0.45 ; 95 \%$ confidence interval $[\mathrm{CI}]=0.23-0.86)$ and rates of myocardial infarction $(\mathrm{OR}=0.49 ; 95 \% \mathrm{CI}=0.26-0.93) .{ }^{7}$ However, these findings have been questioned based on concerns that the statistical approach used by Navarese et al. is biased in how study arms with zero events were handled. ${ }^{9,10}$ Critics demonstrated that use of a few different less-biased conventional methods produced results of consistently smaller magnitude and in 1 case lost statistical significance. Because of the instability and imprecision of these findings, critics urge us to wait for the results of the adequately designed cardiovascular endpoint trials now underway before promoting use of these drugs. Given the increased demand by payers such as Medicare for definitive evidence that interventions improve health outcomes, and not merely intermediate endpoints, ${ }^{19}$ this debate has important implications for coverage policy determinations as well.
Additionally, there has been criticism that even the LDL-C benefits of PCSK9 inhibitors may have been overestimated because of underutilization of high-intensity statin therapy. ${ }^{11,12}$ In the largest PCSK9 inhibitor trial to date, the ODYSSEY LONGTERM trial of alirocumab, ${ }^{20}$ which alone accounts for $45 \%$ of mortality events in the Navarese 2015 meta-analysis, ${ }^{7}$ only $47 \%$ of patients were receiving high-dose statins, despite the trial's focus on high-risk patients. In their published response to this criticism, the ODYSSEY LONG-TERM authors agreed with this limitation and promised that the ongoing ODYSSEY Outcomes study (NCT01663402) will address this uncertainty. ${ }^{21}$

To support the work of the participating organizations of the Drug Effectiveness Review Project, the Pacific Northwest Evidence-based Practice Center conducted a systematic review of the comparative effectiveness of alirocumab and evolocumab versus each another, other lipid-lowering regimens, or placebo. ${ }^{22}$ The purpose of this review was to evaluate the body of evidence for each drug based on the population and comparators studied to better stratify the evidence for decision making with regard for their place in therapy and for selecting a specific PCSK9 inhibitor.

\section{Methods}

For this systematic review, randomized controlled trials (RCTs) of alirocumab or evolocumab were included that reported 1 or more health outcomes (e.g., cardiovascular events), lipid outcomes (e.g., LDL-C), or harms (e.g., withdrawal from study because of adverse events). For cardiovascular events, only those that were adjudicated through a formal process were included; those events that were reported as incidental findings were excluded.

To identify relevant studies, Ovid MEDLINE (through week 2, September 2015), the Cochrane Library databases (2009 through 2015), and Scopus (2010 through 2015) were searched, using drug names as search terms. Additional studies were located by hand searching reference lists of included studies, ClinicalTrials.gov, and requested information from drug manufacturers. Two reviewers, using consensus to resolve disagreements, assessed studies for eligibility. Study characteristics, including baseline patient characteristics, and study results were abstracted by 1 reviewer and checked by a second reviewer for accuracy.

The internal validity (quality) of individual studies were assessed based on predefined criteria developed for the Drug Effectiveness Review Project (see Appendix A for individual study ratings, available in online article). ${ }^{23}$ Individual studies were assigned ratings of good, fair, or poor. Studies with major flaws were rated as poor; those with essentially no flaws were rated as good; and the remainder were rated as fair. Data in studies that were clinically and methodologically similar were pooled using random effects models, and statistical heterogeneity was explored using the I-squared statistic. ${ }^{24}$ 


\section{FIGURE 1 Results of Literature Search}

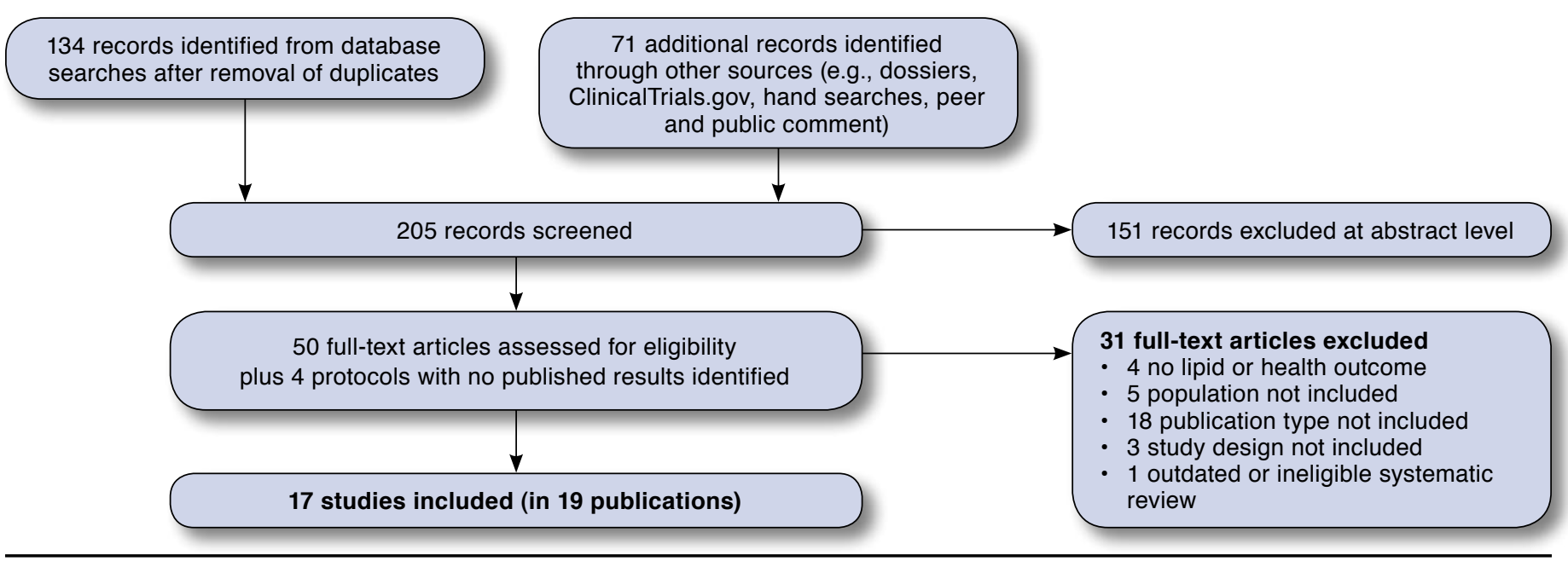

aThe Drug Effectiveness Review Project uses a modified PRISMA flow diagram. ${ }^{46}$

For studies with multiple arms of differing doses, the doses within the FDA-approved dosing range were analyzed. Body of evidence strength was graded for a given key outcome based on the guidance established for the Evidence-based Practice Center Program of the Agency for Healthcare Research and Quality. ${ }^{25}$ This grading assessed the limitations, directness, consistency, and precision of the body of evidence for each outcome and resulted in evidence rating of high strength $(\star \star \star \star)$, moderate strength $(\star \star \star)$, low strength $(\star \star)$, or insufficient $(\star)$ to draw conclusions. In the tables presented in this review, these ratings are shown as stars. Individual study quality and the strength of evidence ratings were dually reviewed with disagreements resolved using consensus.

\section{Results}

For this review, 17 trials were included in 19 publications (Figure 1). ${ }^{20,26-43}$ There are no completed or ongoing studies that directly compared different PCSK9 inhibitors. Study details are summarized in Table 1, and results are shown in Tables 2-4. Study quality assessments and strength of evidence by outcome are presented in Appendices A and B (available in online article). No studies were found to be of poor quality.

\section{Heterozygous and Homozygous Familial Hypercholesterolemia}

Compared with placebo, there was low-strength evidence that alirocumab achieved a higher LDL-C reduction in patients with heterozygous familial hypercholesterolemia who took a maximum statin dose plus ezetimibe, based on 1 fair-quality trial $(\mathrm{N}=77)$. Similar effects were shown for high-density lipoprotein cholesterol (HDL-C), but there was insufficient evidence to draw conclusions about harms. ${ }^{38}$ Evidence for alirocumab compared with placebo in patients with heterozygous familial hypercholesterolemia who took a low- to moderate-intensity statin was insufficient (1 fair-quality RCT, $N=22$ ) ${ }^{39}$ There were no studies of alirocumab in patients with homozygous familial hypercholesterolemia.

Compared with placebo, there is high-strength evidence from two 12-week RCTs (fair- and good-quality, $\mathrm{N}=499$ ) that evolocumab (140 mg every 2 weeks to $420 \mathrm{mg}$ every 4 weeks) achieved a greater LDL-C reduction in patients with heterozygous familial hypercholesterolemia who were largely taking a high-intensity statin plus ezetimibe, with a greater improvement in HDL-C and no differences in harms (moderatestrength evidence). ${ }^{32,34}$ In patients with homozygous familial hypercholesterolemia who took a maximum statin dose and ezetimibe (Table 3), low-strength evidence based on 1 small, good-quality trial $(\mathrm{N}=50)$ suggested that evolocumab $(420 \mathrm{mg}$ every 4 weeks) reduced LDL-C significantly more than placebo at 12 weeks. ${ }^{33}$ There was no difference in HDL-C change, and there was no difference in the percentage of patients with serious adverse events, neurocognitive events, or those withdrawing because of treatment-emergent adverse events.

\section{Statin-Intolerant Patients}

There was no evidence for alirocumab in patients who were intolerant to statins. In statin-intolerant patients, there was low-strength evidence based on 2 fair-quality, 12-week RCTs (GAUSS and GAUSS-2; N=434) that evolocumab (280 mg every 4 weeks or $140 \mathrm{mg}$ every 2 weeks) led to a greater reduction in LDL-C than placebo, with similar effects in HDL-C and harms. ${ }^{40,41}$ There is also low-strength evidence from the 


\section{TABLE 1 Characteristics of Included Studies of Alirocumab and Evolocumab}

\begin{tabular}{|c|c|c|c|c|}
\hline $\begin{array}{l}\text { Study Sample Size } \\
\text { Study Quality } \\
\text { Ratinga }\end{array}$ & Population Eligible for Study & $\begin{array}{l}\text { Study Interventions } \\
\text { Study Duration }\end{array}$ & $\begin{array}{l}\text { Age } \\
\text { Gender (n) } \\
\text { Ethnicity (n) }\end{array}$ & $\begin{array}{l}\text { Other Population } \\
\text { Characteristics (n) }\end{array}$ \\
\hline $\begin{array}{l}\text { Blom, } 2014^{26} \\
\text { DESCARTES } \\
\mathrm{N}=901 \\
\text { Good }\end{array}$ & $\begin{array}{l}\text { Hyperlipidemia and } \\
\text { LDL-C } \geq 75 \mathrm{mg} / \mathrm{dL}\end{array}$ & $\begin{array}{l}\text { Subcutaneous evolocumab } \\
420 \text { mg or placebo every } 4 \\
\text { weeks. } \\
48 \text { weeks }\end{array}$ & $\begin{array}{l}\text { Age: } 56 \mathrm{y} \\
\text { Female: } 52.3 \%(471) \\
\text { White: } 80.4 \%(724) \\
\text { Asian: } 6.3 \%(57) \\
\text { Black: } 8.4 \%(76) \\
\text { Other: } 4.9 \%(44)\end{array}$ & $\begin{array}{l}\text { CAD: } 15.1 \%(136) \\
\text { LDL-C: NR } \\
\text { HDL-C: NR }\end{array}$ \\
\hline $\begin{array}{l}\text { Cannon, } 2015^{27} \\
\text { ODYSSEY COMBO II } \\
\mathrm{N}=720 \\
\text { Good }\end{array}$ & $\begin{array}{l}\text { Hypercholesterolemia. CVD } \\
\text { and LDL-C } \geq 70 \mathrm{mg} / \mathrm{dL} \text { or } \\
\text { no history of CVD but at } \\
\text { high cardiovascular risk and } \\
\text { LDL-C } \geq 100 \mathrm{mg} / \mathrm{dL} \text {. }\end{array}$ & $\begin{array}{l}\text { Subcutaneous alirocumab } \\
75 \text { mg every } 2 \text { weeks or } \\
\text { ezetimibe } 10 \text { mg daily } \\
\text { (both with statins). } \\
104 \text { weeks }\end{array}$ & $\begin{array}{l}\text { Age: } 61.5 \mathrm{y} \\
\text { Female: } 26.4 \%(190) \\
\text { White: } 84.7 \%(610) \\
\text { Black: } 3.9 \%(28) \\
\text { Other: } 11.4 \%(82)\end{array}$ & $\begin{array}{l}\text { CHD: } 90.1 \%(649) \\
\text { LDL-C: } 106 \mathrm{mg} / \mathrm{dL} \\
\text { HDL-C: } 46 \mathrm{mg} / \mathrm{dL} \\
\text { High-intensity statin: } \\
66.7 \%(480)\end{array}$ \\
\hline $\begin{array}{l}\text { Giugliano, } 2012^{28} \\
\text { Desai, } 201443 \\
\text { LAPLACE-TIMI } 57 \\
\mathrm{~N}=631 \\
\text { Good }\end{array}$ & $\begin{array}{l}\text { Hypercholesterolemia while on } \\
\text { statin with LDL-C> } 85 \mathrm{mg} / \mathrm{dL} \text {. }\end{array}$ & $\begin{array}{l}\text { Subcutaneous evolocumab } \\
70 \mathrm{mg}, 105 \mathrm{mg}, 140 \mathrm{mg} \text {, or } \\
\text { placebo every } 2 \text { weeks or } \\
280 \mathrm{mg}, 350 \mathrm{mg}, 420 \mathrm{mg} \text {, or } \\
\text { placebo every } 4 \text { weeks. } \\
12 \text { weeks }\end{array}$ & $\begin{array}{l}\text { Age: } 62 \text { y } \\
\text { Female: } 51.0 \%(320) \\
\text { White: } 89.0 \%(560)\end{array}$ & $\begin{array}{l}\text { CAD: } 30.0 \%(187) \\
\text { LDL-C: } 123 \mathrm{mg} / \mathrm{dL} \\
\text { HDL-C: } 54 \mathrm{mg} / \mathrm{dL}\end{array}$ \\
\hline $\begin{array}{l}\text { Hirayama, } 201429 \\
\text { YUKAWA } \\
\mathrm{N}=310 \\
\text { Fair }\end{array}$ & $\begin{array}{l}\text { Hypercholesterolemia (high } \\
\text { risk for cardiovascular events). }\end{array}$ & $\begin{array}{l}\text { Subcutaneous evolocumab } \\
70 \mathrm{mg}, 140 \mathrm{mg} \text { every } 2 \text { weeks, } \\
280 \mathrm{mg}, 420 \mathrm{mg} \text { every } 4 \text { weeks, } \\
\text { or placebo. } \\
12 \text { weeks }\end{array}$ & $\begin{array}{l}\text { Age: } 61.5 \mathrm{y} \\
\text { Female: } 37.1 \% \text { (114) } \\
\text { Ethnicity: NR }\end{array}$ & $\begin{array}{l}\text { CAD: } 25.1 \%(77) \\
\text { LDL-C: } 139 \mathrm{mg} / \mathrm{dL} \\
\text { HDL-C: } 54 \mathrm{mg} / \mathrm{dL} \\
\text { Intensive statin: } 6.2 \% \text { (19) }\end{array}$ \\
\hline $\begin{array}{l}\text { Kereiakes, } 2015^{30} \\
\text { ODYSSEY COMBO I } \\
\mathrm{N}=316 \\
\text { Fair }\end{array}$ & $\begin{array}{l}\text { Hypercholesterolemia. } \\
\text { LDL-C } \geq 70 \mathrm{mg} / \mathrm{dL} \text { and } \\
\text { established CVD or } \\
\text { LDL-C } \geq 100 \mathrm{mg} / \mathrm{dL} \text { with } \\
\text { CHD risk equivalents. }\end{array}$ & $\begin{array}{l}\text { Subcutaneous alirocumab } \\
75 \text { mg every } 2 \text { weeks or } \\
\text { placebo. } \\
52 \text { weeks }\end{array}$ & $\begin{array}{l}\text { Age: } 63 \text { y } \\
\text { Female: } 34.2 \%(108) \\
\text { White: } 81.6 \%(258) \\
\text { Black: } 16.1 \%(51)\end{array}$ & $\begin{array}{l}\text { CHD: } 78.2 \%(247) \\
\text { LDL-C: } 98 \mathrm{mg} / \mathrm{dL} \\
\text { HDL-C: } 49 \mathrm{mg} / \mathrm{dL} \\
\text { High-intensity statin: } \\
62.7 \%(198) \\
\text { Ezetimibe: } 8.2 \%(26)\end{array}$ \\
\hline $\begin{array}{l}\text { McKenney, } 2012^{31} \\
\mathrm{~N}=183 \\
\text { Fair }\end{array}$ & $\begin{array}{l}\text { Patients with LDL-C } \geq 100 \mathrm{mg} / \\
\mathrm{dL} \text { on stable dose atorvastatin } \\
10 \mathrm{mg}, 20 \mathrm{mg} \text {, or } 40 \mathrm{mg} \text { for } \\
\geq 6 \text { weeks. }\end{array}$ & $\begin{array}{l}\text { Subcutaneous alirocumab } \\
50 \mathrm{mg}, 100 \mathrm{mg}, 150 \mathrm{mg} \text { every } \\
2 \text { weeks; } 200 \mathrm{mg}, 300 \mathrm{mg} \text { every } \\
4 \text { weeks or placebo. } \\
12 \text { weeks }\end{array}$ & $\begin{array}{l}\text { Age: } 57 \text { y } \\
\text { Female: } 52.5 \%(96) \\
\text { White: } 86.3 \%(158) \\
\text { Black: } 12.6 \%(23) \\
\text { Other: } 1.0 \%(2) \\
\text { Hispanic or Latino ethnicity: } \\
21.9 \%(40)\end{array}$ & CAD: $5.5 \%(10)$ \\
\hline $\begin{array}{l}\text { Raal, } 2012^{32} \\
\text { RUTHERFORD } \\
\mathrm{N}=167 \\
\text { Fair }\end{array}$ & $\begin{array}{l}\text { Heterozygous familial hyper- } \\
\text { cholesterolemia with LDL-C } \\
\geq 100 \mathrm{mg} / \mathrm{dL} \text { despite statin } \\
\text { therapy with or without } \\
\text { ezetimibe. }\end{array}$ & $\begin{array}{l}\text { Subcutaneous evolocumab } \\
350 \mathrm{mg}, 420 \mathrm{mg} \text {, or placebo } \\
\text { every } 4 \text { weeks. } \\
12 \text { weeks }\end{array}$ & $\begin{array}{l}\text { Age: } 49.6 \text { y } \\
\text { Female: } 46.7 \%(78) \\
\text { White: } 88.6 \%(148) \\
\text { Asian: } 4.2 \%(7) \\
\text { Black: } 2.4 \%(4) \\
\text { Other: } 4.8 \%(8)\end{array}$ & $\begin{array}{l}\text { CAD: } 21.0 \%(35) \\
\text { LDL-C: } 158 \mathrm{mg} / \mathrm{dL} \\
\text { HDL-C: } 46 \mathrm{mg} / \mathrm{dL} \\
\text { Intensive statin: } 89.8 \% \text { (150) } \\
\text { Ezetimibe use: } 64.7 \% \text { (108) }\end{array}$ \\
\hline $\begin{array}{l}\text { Raal, } 2015^{34} \\
\text { RUTHERFORD-2 } \\
\mathrm{N}=331 \\
\text { Good }\end{array}$ & $\begin{array}{l}\text { Heterozygous familial } \\
\text { hypercholesterolemia with } \\
\text { LDL-C } \geq 100 \mathrm{mg} / \mathrm{dL} \text { despite } \\
\text { statin therapy with or without } \\
\text { ezetimibe. }\end{array}$ & $\begin{array}{l}\text { Subcutaneous evolocumab } \\
140 \mathrm{mg} \text { every } 2 \text { weeks, } 420 \mathrm{mg} \\
\text { or placebo every } 4 \text { weeks. } \\
12 \text { weeks }\end{array}$ & $\begin{array}{l}\text { Age: } 50.6 \mathrm{y} \\
\text { Female: } 42.0 \% \text { (139) } \\
\text { Ethnicity: NR }\end{array}$ & $\begin{array}{l}\text { CAD: } 31.1 \%(103) \\
\text { LDL-C: } 154 \mathrm{mg} / \mathrm{dL} \\
\text { HDL-C: } 50 \mathrm{mg} / \mathrm{dL} \\
\text { Intensive statin: } 87.3 \% \text { (298) } \\
\text { Ezetimibe plus statin: } 61.6 \% \\
\text { (204) }\end{array}$ \\
\hline $\begin{array}{l}\text { Raal, } 2015^{33} \\
\text { TESLA Part B } \\
\mathrm{N}=49 \\
\text { Good }\end{array}$ & $\begin{array}{l}\text { Homozygous familial } \\
\text { hypercholesterolemia with } \\
\text { LDL } \geq 131 \mathrm{mg} / \mathrm{dL} \text {. }\end{array}$ & $\begin{array}{l}\text { Subcutaneous evolocumab } \\
420 \text { mg or placebo every } \\
4 \text { weeks. } \\
12 \text { weeks }\end{array}$ & $\begin{array}{l}\text { Age: } 31 \text { y } \\
\text { Female: } 49.0 \%(24) \\
\text { White: } 90.0 \%(44) \\
\text { Asian: } 4.0 \%(2)\end{array}$ & $\begin{array}{l}\text { CAD: } 43.0 \%(21) \\
\text { LDL-C: } 348 \mathrm{mg} / \mathrm{dL} \\
\text { HDL-C: } 38 \mathrm{mg} / \mathrm{dL} \\
\text { Atorvastatin } \geq 40 \mathrm{mg}: 63.0 \% \\
\text { (31) } \\
\text { Rosuvastatin } \geq 20 \mathrm{mg}: 31.0 \% \\
\text { (15) } \\
\text { Ezetimibe: } 92.0 \%(45)\end{array}$ \\
\hline $\begin{array}{l}\text { Robinson, } 201435 \\
\text { LAPLACE-2 } \\
\mathrm{N}=1,899 \\
\text { Fair }\end{array}$ & $\begin{array}{l}\text { Hypercholesterolemia with } \\
\text { LDL } \geq 150 \mathrm{mg} / \mathrm{dL} \text { (no statin at } \\
\text { screening), } \geq 100 \mathrm{mg} / \mathrm{dL} \\
\text { (nonintensive statin at } \\
\text { screening), or } \geq 80 \mathrm{mg} / \mathrm{dL} \\
\text { (intensive statin at screening). }\end{array}$ & $\begin{array}{l}\text { Subcutaneous evolocumab } \\
140 \text { mg every } 2 \text { weeks (or } 420 \\
\text { mg monthly), ezetimibe } 10 \mathrm{mg} \\
\text { daily, or placebo. } \\
12 \text { weeks }\end{array}$ & $\begin{array}{l}\text { Age: } 60.1 \text { y } \\
\text { Female: } 45.7 \%(868) \\
\text { White: } 94.0 \%(1,782) \\
\text { Black: } 4.0 \%(75) \\
\text { Other: } 2.0 \%(39)\end{array}$ & $\begin{array}{l}\text { CAD: } 22.5 \%(427) \\
\text { LDL-C: } 108.9 \mathrm{mg} / \mathrm{dL} \\
\text { HDL-C: } 53.2 \mathrm{mg} / \mathrm{dL}\end{array}$ \\
\hline
\end{tabular}




\section{TABLE 1 Characteristics of Included Studies of Alirocumab and Evolocumab (continued)}

\begin{tabular}{|c|c|c|c|c|}
\hline $\begin{array}{l}\text { Study Sample Size } \\
\text { Study Quality } \\
\text { Ratinga }\end{array}$ & Population Eligible for Study & $\begin{array}{l}\text { Study Interventions } \\
\text { Study Duration }\end{array}$ & $\begin{array}{l}\text { Age } \\
\text { Gender (n) } \\
\text { Ethnicity (n) }\end{array}$ & $\begin{array}{l}\text { Other Population } \\
\text { Characteristics (n) }\end{array}$ \\
\hline $\begin{array}{l}\text { Robinson, } 2015^{20} \\
\text { ODYSSEY LONG } \\
\text { TERM } \\
\mathrm{N}=2,341 \\
\text { Good }\end{array}$ & $\begin{array}{l}\text { Heterozygous familial } \\
\text { hypercholesterolemia or with } \\
\text { established CHD or a CHD } \\
\text { risk equivalent and } \\
\text { LDL-C } \geq 70 \mathrm{mg} / \mathrm{dL} \text {. }\end{array}$ & $\begin{array}{l}\text { Subcutaneous alirocumab } \\
150 \text { mg or placebo every } \\
2 \text { weeks. } \\
78 \text { weeks }\end{array}$ & $\begin{array}{l}\text { Age: } 60.5 \mathrm{y} \\
\text { Female: } 37.8 \%(884) \\
\text { White: } 92.7 \%(2,171)\end{array}$ & $\begin{array}{l}\text { HeFH: } 17.7 \%(415) \\
\text { CHD: } 68.6 \%(1,607) \\
\text { CHD risk equivalent: } 41.1 \% \\
\text { (962) } \\
\text { LDL-C: } 122 \mathrm{mg} / \mathrm{dL} \\
\text { HDL-C: } 50 \mathrm{mg} / \mathrm{dL} \\
\text { Intensive statin: } 46.8 \%(1,095) \\
\text { Ezetimibe: } 14.3 \%(334)\end{array}$ \\
\hline $\begin{array}{l}\text { Roth, } 2012^{36} \\
\mathrm{~N}=92 \\
\text { Fair }\end{array}$ & $\begin{array}{l}\text { Primary hypercholesterolemia. } \\
\text { LDL-C } \geq 100 \mathrm{mg} / \mathrm{dL} \text { despite } \\
\text { atorvastatin. }\end{array}$ & $\begin{array}{l}\text { Subcutaneous alirocumab } \\
150 \mathrm{mg} \text { every } 2 \text { weeks + } \\
80 \mathrm{mg} \text { atorvastatin; + } 10 \mathrm{mg} \\
\text { atorvastatin; or placebo + } \\
80 \mathrm{mg} \text { atorvastatin. } \\
8 \text { weeks }\end{array}$ & $\begin{array}{l}\text { Age: } 56.9 \text { y } \\
\text { Female: } 60.0 \%(55) \\
\text { White: } 87.0 \%(80) \\
\text { Black: } 13.0 \%(12)\end{array}$ & $\begin{array}{l}\text { CAD: } 3.0 \%(3) \\
\text { LDL-C: } 123 \mathrm{mg} / \mathrm{dL} \\
\text { HDL-C: } 55 \mathrm{mg} / \mathrm{dL}\end{array}$ \\
\hline $\begin{array}{l}\text { Sabatine, } 2015^{37} \\
\text { OSLER-1 } \\
\text { OSLER-2 } \\
\mathrm{N}=4,465 \\
\text { Fair }\end{array}$ & $\begin{array}{l}\text { Heterozygous familial hyper- } \\
\text { cholesteremia and statin } \\
\text { intolerant. Completed } 1 \text { of } 12 \\
\text { phase } 2 \text { or } 3 \text { studies of } \\
\text { evolocumab. } \\
\text { LDL } \geq 100 / 150 \mathrm{mg} / \mathrm{dL} \text { without } \\
\text { statin/background anti-lipid } \\
\text { therapy/statin-intolerant. } \\
\text { LDL } \geq 75 / 80 / 85 / 100 / 116 \mathrm{mg} / \mathrm{dL} \\
\text { with statin/background anti- } \\
\text { lipid therapy. }\end{array}$ & $\begin{array}{l}\text { OSLER-1: Subcutaneous } \\
\text { evolocumab } 420 \text { mg once per } \\
\text { month + standard therapy vs. } \\
\text { standard therapy alone. } \\
56 \text { weeks } \\
\text { OSLER-2: Subcutaneous } \\
\text { evolocumab } 420 \text { mg once per } \\
\text { month or } 140 \text { mg every } 2 \\
\text { weeks + standard therapy } \\
\text { vs. standard therapy alone. } \\
48 \text { weeks }\end{array}$ & $\begin{array}{l}\text { Age: } 58 \mathrm{y} \\
\text { Female: } 49.5 \%(2,210) \\
\text { White: } 85.7 \%(3,826)\end{array}$ & $\begin{array}{l}\text { Known familial } \\
\text { hypercholesterolemia: } \\
\text { 9.9\% (440) } \\
\text { Any CAD: } 20.1 \% \text { (896) } \\
\text { Family history of premature: } \\
\text { CAD: } 24.3 \%(1,086) \\
\text { Median LDL-C: } 120 \mathrm{mg} / \mathrm{dL} \\
\text { Median HDL-C: } 51 \mathrm{mg} / \mathrm{dL}\end{array}$ \\
\hline $\begin{array}{l}\text { Stein, } 2012^{38} \\
\mathrm{~N}=77 \\
\text { Fair }\end{array}$ & $\begin{array}{l}\text { Heterozygous familial } \\
\text { hypercholesterolemia. } \\
\text { LDL-C } \geq 100 \mathrm{mg} / \mathrm{dL} \text {. }\end{array}$ & $\begin{array}{l}\text { Subcutaneous alirocumab } \\
150 \mathrm{mg}, 200 \mathrm{mg} \text {, or } 300 \mathrm{mg} \\
\text { every } 4 \text { weeks or } 150 \mathrm{mg} \text { every } \\
2 \text { weeks or placebo. } \\
12 \text { weeks }\end{array}$ & $\begin{array}{l}\text { Age: } 53.4 \text { y } \\
\text { Female: } 39.0 \%(30) \\
\text { White: } 95.0 \%(73)\end{array}$ & $\begin{array}{l}\text { CAD: } 42.0 \%(32) \\
\text { LDL-C } 155 \mathrm{mg} / \mathrm{dL} \\
\text { Maximum statin dose: } \\
77.0 \%(59) \\
\text { Ezetimibe use: } 71.0 \%(55)\end{array}$ \\
\hline $\begin{array}{l}\text { Stein, } 2012^{39} \\
\mathrm{~N}=61 \\
\text { Fair }\end{array}$ & $\begin{array}{l}\text { Heterozygous and } \\
\text { nonheterozygous familial } \\
\text { hypercholesterolemia. } \\
\text { Atorvastatin with LDL-C } \geq 100 \\
\mathrm{mg} / \mathrm{dL} \text { or modified diet with } \\
\text { LDL-C }=130 \mathrm{mg} / \mathrm{dL} \text {. }\end{array}$ & $\begin{array}{l}\text { Subcutaneous alirocumab } \\
50 \mathrm{mg}, 100 \mathrm{mg} \text {, or } 150 \mathrm{mg} \text { vs. } \\
\text { placebo with and without } \\
\text { atorvastatin. } \\
106 \text { days }\end{array}$ & $\begin{array}{l}\text { Age: } 47 \mathrm{y} \\
\text { Female: } 30.0 \%(18) \\
\text { White: } 95.0 \%(58) \\
\text { Black: } 5.0 \% \text { (3) }\end{array}$ & $\begin{array}{l}\text { LDL-C: } 138 \mathrm{mg} / \mathrm{dL} \\
\text { HDL-C: } 48 \mathrm{mg} / \mathrm{dL} \\
\text { Atorvastatin } 10 \mathrm{mg}: 26.0 \%(15) \\
\text { Atorvastatin } 20 \mathrm{mg}: 23.0 \%(14) \\
\text { Atorvastatin } 40 \mathrm{mg}: 18.0 \%(11)\end{array}$ \\
\hline $\begin{array}{l}\text { Stroes, } 201440 \\
\text { GAUSS-2 } \\
\mathrm{N}=307 \\
\text { Fair }\end{array}$ & $\begin{array}{l}\text { Statin intolerant to } \geq 2 \text { statins. } \\
\text { LDL-C }>\text { NCEP ATP III goal. }\end{array}$ & $\begin{array}{l}\text { Ezetimibe daily + placebo every } \\
2 \text { weeks, evolocumab } 140 \\
\text { mg every } 2 \text { weeks + placebo } \\
\text { daily, ezetimibe daily + placebo } \\
\text { monthly, evolocumab } 420 \mathrm{mg} \\
\text { monthly + placebo daily. } \\
12 \text { weeks }\end{array}$ & $\begin{array}{l}\text { Age: } 61.5 \mathrm{y} \\
\text { Female: } 45.9 \%(141) \\
\text { White: } 93.5 \%(287) \\
\text { Black: } 2.3 \%(7)\end{array}$ & $\begin{array}{l}\geq 2 \text { cardiovascular risk factors } b \text { : } \\
47.9 \% \text { (147) }\end{array}$ \\
\hline $\begin{array}{l}\text { Sullivan, } 2012^{41} \\
\text { GAUSS } \\
\mathrm{N}=160 \\
\text { Fair }\end{array}$ & $\begin{array}{l}\text { Statin intolerant to at least } \\
1 \text { statin. }\end{array}$ & $\begin{array}{l}\text { Evolocumab } 280 \mathrm{mg}, 350 \mathrm{mg}, \\
\text { and } 420 \mathrm{mg} \text {; evolocumab } 420 \\
\text { mg with ezetimibe } 10 \mathrm{mg} \text {; } \\
\text { ezetimibe } 10 \mathrm{mg}+\text { placebo (all } \\
\text { administered subcutaneously } \\
\text { every } 4 \text { weeks). } \\
12 \text { weeks }\end{array}$ & $\begin{array}{l}\text { Age: } 61.8 \mathrm{y} \\
\text { Female: } 63.7 \%(100) \\
\text { White: } 88.5 \%(139) \\
\text { Black: } 5.1 \%(8)\end{array}$ & $\begin{array}{l}\text { NCEP CHD risk category: } \\
\text { High: } 39.5 \%(62) \\
\text { Moderately high: } 10.2 \%(16) \\
\text { Moderate: } 28.0 \%(44) \\
\text { Lower: } 22.3 \%(35)\end{array}$ \\
\hline
\end{tabular}

a Study quality ratings = assessments of individual study internal validity.

${ }^{b}$ Cardiovascular risk factors: current cigarette use, type 2 diabetes, hypertension, family history of premature CHD, and low HDL-C.

ATP III =Adult Treatment Panel III; CAD= coronary artery disease; CHD=coronary heart disease; CVD =cardiovascular disease; HDL-C = high-density lipoprotein

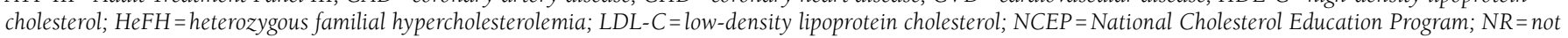
reported; $y=$ years. 
GAUSS study $(\mathrm{N}=62)$ that the combination of evolocumab (420 mg every 4 weeks) plus ezetimibe $(10 \mathrm{mg}$ ) led to a greater percentage of LDL-C reduction than ezetimibe $(10 \mathrm{mg})$ alone, but there was insufficient evidence to draw conclusions on other outcomes. ${ }^{41}$

\section{Secondary Treatment in Patients at High Cardiovascular Risk (Not Achieving Study Targets with First-Line Therapies)}

Several studies evaluated a PCSK9 inhibitor in patients with varying levels of cardiovascular risk, who had not achieved an LDL-C of $\leq 100 \mathrm{mg} / \mathrm{dL}$ or $\leq 70$ or $75 \mathrm{mg} / \mathrm{dL}$ using mainly statin-based therapy before randomization. Very few patients had familial forms of hypercholesterolemia in these studies. In high-risk patients, moderate-strength evidence based on a good-quality trial (ODYSSEY COMBO II, N=720) demonstrated that alirocumab (75 $\mathrm{mg}$ to $150 \mathrm{mg}$ given every 2 weeks) resulted in a higher proportion of patients with high cardiovascular risk reaching the study goal of LDL-C $<70 \mathrm{mg} / \mathrm{dL}$ at 24 weeks (relative risk $[\mathrm{RR}]=1.70,95 \% \mathrm{CI}=1.46-1.95$ ) than ezetimibe $(10 \mathrm{mg}) .{ }^{27}$ Similarly, the difference in the percentage of change in LDL-C and HDL-C at 24 weeks was greater with alirocumab $(-29.8 \%$ and $8.1 \%, P<0.001)$. Moderate-strength evidence found that there was no difference in overall adverse event reporting between alirocumab and ezetimibe and that the rate for reporting any adverse event was high (69\%). Lowstrength evidence found that withdrawal because of adverse events and serious adverse events were not different between the groups. Low-strength evidence suggested a higher rate of injection-site reactions with alirocumab than with placebo injection plus ezetimibe, but this estimate was imprecise (wide confidence interval, inadequate sample size to evaluate this outcome). Neurocognitive events were rare.

Based on 2 trials (ODYSSEY COMBO I and ODYSSEY Long-Term; $N=2,656)$, there was high-strength evidence that alirocumab (75 mg to $150 \mathrm{mg}$ given every 2 weeks) resulted in a higher proportion of patients with high cardiovascular risk reaching the study goal of LDL-C $<70 \mathrm{mg} / \mathrm{dL}$ at 24 weeks than placebo (pooled $\mathrm{RR}=9.65,95 \% \mathrm{CI}=7.7-12.0$ ). ${ }^{20,30}$ The difference in the percentage of reduction in LDL-C and HDL-C was also greater. High-strength evidence found no statistical difference in overall adverse event reporting and that the rate for reporting any adverse event was high (75\%). Moderate-strength evidence found that withdrawal because of adverse events and serious adverse events were also not different between groups. Low-strength evidence suggested that the risk of injection-site reactions (pooled $\mathrm{RR}=1.4,95 \% \mathrm{CI}=0.98-2.1$ ) or neurocognitive events were not increased, although the estimates were imprecise because of few events.

In a comparison of evolocumab and ezetimibe (both with statin therapy) in patients with high cardiovascular risk, the LAPLACE-2 study ( $\mathrm{N}=329$ for this comparison) provided low-strength evidence that when added to either atorvastatin
(10 $\mathrm{mg}$ or $80 \mathrm{mg}$ ), compared with ezetimibe (10 mg), evolocumab (420 mg monthly) resulted in higher rates of meeting an LDL-C target of $<70 \mathrm{mg} / \mathrm{dL}$ at 12 weeks, with similar rates of patients with overall adverse events. ${ }^{35}$ This study provided insufficient evidence to draw conclusions about HDL-C, serious adverse events, or withdrawal because of adverse events because of the small magnitude of change or event rates. In patients with high cardiovascular risk, a small 12-week ( $\mathrm{N}=104$ for placebo comparison) study provided low-strength evidence that evolocumab (420 mg monthly) resulted in higher rates of meeting LDL-C targets of $<100 \mathrm{mg} / \mathrm{dL}$ and $<70 \mathrm{mg} / \mathrm{dL}$ when added to statins in Japanese patients, compared with placebo. ${ }^{29}$ There was greater mean change in LDL-C but insufficient evidence to draw conclusions about other outcomes.

There was moderate- and low-strength evidence of no difference in adjudicated cardiovascular events between alirocumab and ezetimibe at 52 weeks or between alirocumab and placebo at 52-78 weeks (Table 4) ${ }^{20,27,30}$ For evolocumab, adjudicated cardiovascular events were reported as secondary or post hoc outcomes, but evidence was insufficient to draw conclusions because of too few events (imprecise estimates), study limitations, and lack of ability to verify findings across multiple studies (Table 4). ${ }^{29,37}$

\section{Secondary Treatment in Patients at Varied Cardiovascular Risk (Not Achieving Study Targets with First-Line Therapies)}

Low-strength evidence from 2 small ( $\mathrm{N}=154$ total) fair-quality RCTs indicated that in patients stabilized on statins who have not achieved an LDL-C of $<100 \mathrm{mg} / \mathrm{dL}$, alirocumab (150 mg subcutaneously every 2 weeks for 8-10 weeks) resulted in significantly more patients achieving study goal (LDL-C $<100 \mathrm{mg} /$ dL) and a greater percentage of reductions (49\%-67\% more) than statins alone. ${ }^{31,36}$ Evidence for adverse events and in subgroups, compared with statins alone, was insufficient because of small sample sizes.

In short-term comparisons of evolocumab and placebo, LAPLACE-TIMI 57 and LAPLACE-2 ( $=996$ for placebo comparison) provided high-strength evidence that, at 12 weeks in patients with varying risk levels and not meeting LDL targets, significantly more patients taking evolocumab (420 mg monthly) than taking placebo (both with statin therapy) achieved an LDL-C of $<70 \mathrm{mg} / \mathrm{dL}$ and had a greater percentage of reduction in LDL-C. ${ }^{28,35}$ There is also moderate-strength evidence of modest HDL-C increases with evolocumab (420 mg monthly) and moderate- to high-strength evidence of no differences in adverse events. Based on 1 good-quality longer-term trial ( $\mathrm{N}=901 ; 52$ weeks), there is moderate-strength evidence that evolocumab (420 mg given every 4 weeks) also results in significantly more patients achieving a goal of LDL-C $<70 \mathrm{mg} /$ $\mathrm{dL}$, compared with placebo; low-strength evidence of a modest increase in HDL-C; and evidence of no difference in harms (low- and moderate-strength evidence depending on outcome). 
TABLE 2 Lipid and Adverse Event Outcomes for Alirocumab and Evolocumab

\begin{tabular}{|c|c|c|c|c|c|c|c|}
\hline Intervention & $\begin{array}{l}\text { Study, n } \\
\text { Sample Size } \\
\text { Endpoint }\end{array}$ & $\begin{array}{l}\text { Concomitant } \\
\text { Lipid Therapy } \\
\text { (\% High-Dose) } \\
\text { Baseline LDL-C }\end{array}$ & $\begin{array}{c}\text { PCSK9 } \\
\text { Inhibitor Dose }\end{array}$ & $\begin{array}{l}\text { Difference in } \\
\text { LDL-C Change }\end{array}$ & $\begin{array}{l}\text { Difference in \% } \\
\text { Meeting } \\
\text { LDL-C Goal }\end{array}$ & $\begin{array}{l}\text { Difference in } \\
\text { HDL-C Change }\end{array}$ & Harms \\
\hline \multicolumn{8}{|c|}{ Heterozygous familial hypercholesterolemia versus placebo } \\
\hline Alirocumab & $\begin{array}{l}2 \text { RCTs }^{38,39} \\
\mathrm{~N}=99 \\
12 \text { weeks }\end{array}$ & $\begin{array}{l}\text { High-dose statin } \\
(51.0 \%-77.0 \%)+ \\
\text { ezetimibe. } \\
151-170 \mathrm{mg} / \mathrm{dL}\end{array}$ & $\begin{array}{l}150 \mathrm{mg}, 200 \mathrm{mg}, \\
\text { or } 300 \mathrm{mg} \text { every } \\
4 \text { weeks or } 150 \\
\text { mg every } 2 \text { weeks }\end{array}$ & $\begin{array}{l}-8.0 \% \text { to }-57.4 \% \\
\star \star\end{array}$ & NR & $\begin{array}{l}150 \text { mg every } \\
2 \text { weeks: } 12.3 \% \\
(P=0.050) \\
\text { Other doses NSD } \\
\star \star\end{array}$ & $\star$ \\
\hline Evolocumab & $\begin{array}{l}2 \text { RCTs } 32,34 \\
N=499 \\
12 \text { weeks }\end{array}$ & $\begin{array}{l}\text { High-intensity } \\
\text { statin }(89.7 \%)+ \\
\text { ezetimibe. } \\
150-155 \mathrm{mg} / \mathrm{dL}\end{array}$ & $\begin{array}{l}140 \text { mg every } \\
2 \text { weeks to } 420 \\
\text { mg every } 4 \text { weeks }\end{array}$ & $\begin{array}{l}-44.1 \% \text { to }-61.3 \% \\
\star \star \star \star\end{array}$ & NR & $\begin{array}{l}6.8 \%(P<0.010) \\
\text { to } 9.2 \%(95 \% \\
C I=4.7 \%-13.7 \%) \\
\star \star \star\end{array}$ & 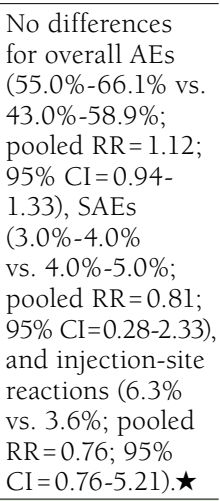 \\
\hline \multicolumn{8}{|c|}{ High cardiovascular risk (not achieved LDL-C targets $<100 \mathrm{mg} / \mathrm{dL}$ or $<70 \mathrm{mg} / \mathrm{dL}$ ) } \\
\hline \multicolumn{8}{|c|}{ Versus ezetimibe $10 \mathrm{mg}$} \\
\hline Alirocumab & $\begin{array}{l}1 \mathrm{RCT}^{27} \\
\mathrm{~N}=720 \\
24 \text { weeks }\end{array}$ & $\begin{array}{l}\text { Statin, range of } \\
\text { doses }(66.6 \%) \text {. } \\
106 \mathrm{mg} / \mathrm{dL}\end{array}$ & $\begin{array}{l}75 \text { to } 150 \mathrm{mg} \\
\text { every } 2 \text { weeks }\end{array}$ & $\begin{array}{l}-29.8 \%(P<0.001) \\
\star \star \star\end{array}$ & $\begin{array}{l}\text { LDL goal } \\
<70 \mathrm{mg} / \mathrm{dL}: \\
\mathrm{RR}=1.70(95 \% \\
\mathrm{CI}=1.46-1.95) \\
\star \star \star\end{array}$ & $\begin{array}{l}8.1 \%(P<0.001) \\
\star \star \star\end{array}$ & $\begin{array}{l}\text { No differences } \\
\text { for overall AEs, } \\
\text { WAEs, or SAEs. } \\
\star \star \star \text { More } \\
\text { injection site } \\
\text { reactions with } \\
\text { alirocumab }(2.5 \% \\
\text { vs. } 0.8 \%) \star \star\end{array}$ \\
\hline Evolocumab & $\begin{array}{l}1 \mathrm{RCT}^{35} \\
\mathrm{~N}=329 \text { for } \\
420 \mathrm{mg} \text { dose or } \\
\text { ezetimibe } \\
12 \text { weeks }\end{array}$ & $\begin{array}{l}\text { Statin, range of } \\
\text { doses }(37.5 \%) \text {. } \\
126-129 \mathrm{mg} / \mathrm{dL} \\
\text { or } 92-94 \mathrm{mg} / \mathrm{dL}\end{array}$ & $\begin{array}{l}420 \text { mg every } \\
4 \text { weeks }\end{array}$ & NR & $\begin{array}{l}\text { LDL goal } \\
<70 \mathrm{mg} / \mathrm{dL} \text { with } \\
\text { atorvastatin } \\
10 \mathrm{mg}: 85.8 \% \text { vs. } \\
5.6 \% \text {; unadjusted } \\
\text { RR }=5.22 \text { (95\% } \\
\text { CI }=3.00-9.69) \\
\text { LDL goal } \\
<70 \text { mg/dL with } \\
\text { atorvastatin } \\
80 \mathrm{mg}: 92.5 \% \\
\text { vs. } 62.3 \% ; \\
\text { unadjusted } \\
\text { RR }=1.47 \text { (95\% } \\
\text { CI }=1.23-1.88) \\
\star \star \\
\end{array}$ & $\star$ & $\begin{array}{l}\text { Similar rates of } \\
\text { overall AEs } \star \star \\
\text { but } \star \text { on other } \\
\text { harms outcomes. }\end{array}$ \\
\hline \multicolumn{8}{|l|}{ Versus placebo } \\
\hline Alirocumab & $\begin{array}{l}2 \text { RCTs }^{20,30} \\
\mathrm{~N}=2,656 \\
24 \text { weeks }\end{array}$ & $\begin{array}{l}\text { High-dose statin } \\
(46.8 \%-63.1 \%) . \\
100-123 \mathrm{mg} / \mathrm{dL}\end{array}$ & $\begin{array}{l}75 \text { to } 150 \mathrm{mg} \\
\text { every } 2 \text { weeks }\end{array}$ & $\begin{array}{l}-45.9 \% \text { to }-61.9 \% \\
(P<0.001) \\
\text { LDL goal } \\
<70 \mathrm{mg} / \mathrm{dL}: \\
\mathrm{RR}=9.65(95 \% \\
\mathrm{CI}=7.7-12.0) \\
\star \star \star \star\end{array}$ & $\begin{array}{l}\text { LDL goal }<70 \\
\text { mg/dL: RR }=9.65 \\
(95 \% \mathrm{CI}=7.7- \\
12.0) \star \star \star \star\end{array}$ & $\begin{array}{l}7.3 \% \text { to } 7.6 \% \\
(P<0.001) \\
\star \star \star \star\end{array}$ & $\begin{array}{l}\text { No difference } \\
\text { in overall AEs, } \\
\text { WAEs, SAEs. } \\
\star \star \star \star \text { to } \star \star \star \\
\text { No difference } \\
\text { in injection-site } \\
\text { reactions (pooled } \\
\text { RR }=1.4 ; 95 \% \\
C I=0.98-2.1 \text { ) or } \\
\text { neurocognitive } \\
\text { events (pooled } \\
\text { RR }=1.8 ; 95 \% \\
C I=0.37-8.5 \text { ). } \star \star\end{array}$ \\
\hline
\end{tabular}


TABLE 2 Lipid and Adverse Event Outcomes for Alirocumab and Evolocumab (continued)

\begin{tabular}{|c|c|c|c|c|c|c|c|}
\hline Intervention & $\begin{array}{l}\text { Study, } \mathbf{n} \\
\text { Sample Size } \\
\text { Endpoint }\end{array}$ & $\begin{array}{l}\text { Concomitant } \\
\text { Lipid Therapy } \\
\text { (\% High-Dose) } \\
\text { Baseline LDL-C }\end{array}$ & $\begin{array}{c}\text { PCSK9 } \\
\text { Inhibitor Dose }\end{array}$ & $\begin{array}{l}\text { Difference in } \\
\text { LDL-C Change }\end{array}$ & $\begin{array}{c}\text { Difference in \% } \\
\text { Meeting } \\
\text { LDL-C Goal }\end{array}$ & $\begin{array}{l}\text { Difference in } \\
\text { HDL-C Change }\end{array}$ & Harms \\
\hline Evolocumab & $\begin{array}{l}1 \mathrm{RCT} 29 \\
\mathrm{~N}=310 \\
12 \text { weeks }\end{array}$ & $\begin{array}{l}\text { High-dose statin } \\
\text { (5.9\%; } 24.8 \% \\
\text { per Japanese } \\
\text { standard). } \\
139 \mathrm{mg} / \mathrm{dL}\end{array}$ & $\begin{array}{l}420 \text { mg every } \\
4 \text { weeks }\end{array}$ & $\begin{array}{l}-63.9 \%(P<0.001) \\
\star \star\end{array}$ & $\begin{array}{l}\text { LDL goal } \\
<100 \mathrm{mg} / \mathrm{dL}: \\
96.0 \% \text { vs. } 1.0 \% \\
(P<0.001) \\
\text { LDL goal } \\
<70 \mathrm{mg} / \mathrm{dL}: \\
82.0 \% \text { vs. } 0.0 \% \\
(P<0.001) \\
\star \star\end{array}$ & $\star$ & $\star$ \\
\hline \multicolumn{8}{|c|}{ Varied cardiovascular risk (not achieved LDL-C targets $<100 \mathrm{mg} / \mathrm{dL}$ or $<70 \mathrm{mg} / \mathrm{dL}$ ) versus placebo } \\
\hline Alirocumab & $\begin{array}{l}2 \text { RCTs } 31,36 \\
\mathrm{~N}=124 \text { at } \\
150 \text { mg dose } \\
10 \text { weeks }\end{array}$ & $\begin{array}{l}\text { Statin, range } \\
\text { of doses }(0.0 \% \text { - } \\
66.3 \%) . \\
123-124 \mathrm{mg} / \mathrm{dL}\end{array}$ & $\begin{array}{l}150 \text { mg every } \\
2 \text { weeks }\end{array}$ & $\begin{array}{l}-49.0 \% \text { to }-67.0 \% \\
\star \star\end{array}$ & $\begin{array}{l}\text { LDL }<100 \mathrm{mg} / \mathrm{dL}: \\
100.0 \% \text { vs. } 16.1 \% \\
\text { to } 52.0 \%(150 \mathrm{mg} \\
\text { every } 2 \text { weeks } \\
\star \star\end{array}$ & $\begin{array}{l}6.3 \% \text { to } 8.5 \% \\
\star \star\end{array}$ & $\star$ \\
\hline Evolocumab & $\begin{array}{l}2 \text { RCTs } 28,35 \\
\mathrm{~N}=1,375 \\
12 \text { and } 52 \text { weeks }\end{array}$ & $\begin{array}{l}\text { Statin, range of } \\
\text { doses accord- } \\
\text { ing to risk level } \\
(29.0 \%-37.5 \%) \text {. } \\
104 \mathrm{mg} / \mathrm{dL}\end{array}$ & $\begin{array}{l}420 \mathrm{mg} \text { every } \\
4 \text { weeks }\end{array}$ & $\begin{array}{l}52 \text { weeks: }-57.0 \% \\
( \pm 2.1 \mathrm{SD}) \\
\star \star \star \\
12 \text { weeks: }-53.0 \% \\
(95 \% \mathrm{CI}=56.0- \\
44.6) \text { to }-70.5 \% \\
(95 \% \mathrm{CI}=-79.8 \\
\text { to }-61.2)\end{array}$ & $\begin{array}{l}52 \text { weeks: LDL } \\
\text { goal }<70 \mathrm{mg} / \mathrm{dL}: \\
82.3 \% \text { vs. } 6.4 \% \\
(P<0.001) \\
\star \star \star \\
12 \text { weeks: LDL } \\
\text { goal }<70 \mathrm{mg} / \mathrm{dL}: \\
71.8 \%-94.5 \% \\
\text { vs. } 0 \%-9.3 \% \\
(P<0.001) \\
\star \star \star \star\end{array}$ & $\begin{array}{l}52 \text { weeks: } 5.4 \% \\
(P<0.001) \\
12 \text { weeks: } 4.5 \% \\
(95 \% \mathrm{CI}=0.4-8.7) \\
\text { to } 9.1 \%(95 \% \\
\mathrm{CI}=4.4-13.7) \\
\star \star \text { to } \star \star \star\end{array}$ & $\begin{array}{l}52 \text { weeks: no } \\
\text { differences } \star \star \\
\text { to } \star \star \star \\
12 \text { weeks: } \\
\text { more overall } \\
\text { AEs }(60.0 \% \text { vs. } \\
42.0 \%) \text {, no } \\
\text { difference in } \\
\text { WAEs, SAEs, or } \\
\text { injection site } \\
\text { reactions } \star \star \star \text { to } \\
\star \star \star \star\end{array}$ \\
\hline
\end{tabular}

Note: Strength of evidence: $\star \star \star \star=$ High; $\star \star \star=$ Moderate; $\star \star=$ Low; $\star=$ Insufficient.

$A E S=$ adverse events; $C I=$ confidence interval; $H D L-C=$ high-density lipoprotein cholesterol; $L D L-C=$ low-density lipoprotein cholesterol; NR=not reported; NSD =no significant difference; $P C S K 9=$ proprotein convertase subtilisin /kexin type 9; $R C T=$ randomized controlled trial; $R R=$ relative risk; SAEs = serious adverse events; $S D=$ stan dard deviation; WAEs = withdrawal due to adverse events.

\section{Varied Populations: Heterozygous Familial, Statin Intolerant, and Not at Target for Risk Level}

There is moderate-strength evidence, based on a pooled analysis of 2 open-label extension studies (OSLER 1 and 2), of patients completing 1 of 12 previous trials (patients not at target, with heterozygous familial hypercholesterolemia, or statin intolerance; $\mathrm{N}=4,465$ ), that evolocumab (420 mg monthly or $140 \mathrm{mg}$ every 2 weeks plus standard care-primarily statins) reduced LDL-C by $61 \%$ more than standard care alone at 12 weeks. ${ }^{37}$ This reduction was largely sustained at 48 weeks (58.4\% more than usual care at week 48). This analysis of the 2 studies also provided low-strength evidence of a greater proportion of patients meeting an LDL-C goal of $<100 \mathrm{mg} / \mathrm{dL}$ or $<70 \mathrm{mg} / \mathrm{dL}$ and a greater increase in HDL-C at 12 weeks than with standard therapy alone.

There is low-strength evidence that slightly more patients on evolocumab experienced any adverse event at 12 weeks, compared with statins alone, without differences in serious adverse events but insufficient evidence to draw conclusions about other adverse event outcomes.

\section{Discussion}

This systematic review of PCSK9 inhibitor drugs finds low- to high-strength evidence of moderate-to-large magnitude reduction in LDL-C when added to statin therapy in patients with familial forms of hypercholesterolemia and alone or added to ezetimibe in those who are intolerant of statins. Although there are no direct comparison studies, and the lipid outcomes are fairly similar across the trials, the strength of this evidence varies by population and by drug. In patients with heterozygous hypercholesterolemia, the trials of evolocumab were larger (499 vs. 98), and the strength of the evidence was consistently stronger than for alirocumab (moderate to high vs. low or insufficient; Table 2). In contrast, the evidence for patients with high cardiovascular risk is stronger for alirocumab. Studies comparing alirocumab with ezetimibe were somewhat larger (720 vs. 329), twice as long (24 weeks vs. 12 weeks), and the strength of evidence was better (low to moderate vs. low and insufficient) than those of evolocumab. Studies comparing alirocumab with placebo in this population were much larger (2,656 vs. 310$)$, twice as long ( 24 weeks vs. 12 weeks), and had much better 
TABLE 3 Evidence for Evolocumab in Other Populations

\begin{tabular}{|c|c|c|c|c|c|c|}
\hline $\begin{array}{l}\text { Study, } \mathbf{n} \\
\text { Sample Size } \\
\text { Endpoint }\end{array}$ & $\begin{array}{l}\text { Concomitant Lipid } \\
\text { Therapy } \\
\text { (\% High-Dose) } \\
\text { Baseline LDL-C }\end{array}$ & $\begin{array}{c}\text { PCSK9 } \\
\text { Inhibitor Dose }\end{array}$ & $\begin{array}{l}\text { Difference in } \\
\text { LDL-C Change }\end{array}$ & $\begin{array}{c}\text { Difference in \% } \\
\text { Meeting LDL-C Goal }\end{array}$ & $\begin{array}{l}\text { Difference in } \\
\text { HDL-C Change }\end{array}$ & Harms \\
\hline \multicolumn{7}{|c|}{ Homozygous familial hypercholesterolemia versus placebo } \\
\hline $\begin{array}{l}\mathrm{RCT}^{33} \\
\mathrm{~N}=50 \\
12 \text { weeks }\end{array}$ & $\begin{array}{l}\text { High-dose statin } \\
(94.0 \%)+\text { ezetimibe. } \\
348 \mathrm{mg} / \mathrm{dL}\end{array}$ & $\begin{array}{l}420 \mathrm{mg} \text { every } 4 \\
\text { weeks }\end{array}$ & $\begin{array}{l}-32.1 \%(95 \% \\
C I=-45.1 \text { to }-19.2) \\
\star \star\end{array}$ & NR & $\begin{array}{l}-0.1 \%(P=N S D) \\
\star \star\end{array}$ & $\begin{array}{l}\text { No differences in } \\
\text { overall AEs } \\
\star \star \\
\star \text { for specific AEs }\end{array}$ \\
\hline \multicolumn{7}{|c|}{ Unable to use statins (evolocumab alone or combined with ezetimibe $10 \mathrm{mg}$ versus ezetimibe $10 \mathrm{mg}$ alone) } \\
\hline $\begin{array}{l}2 \text { RCTs } 40,41 \\
N=496 \\
12 \text { weeks }\end{array}$ & $\begin{array}{l}\text { None. } \\
192-195 \mathrm{mg} / \mathrm{dL}\end{array}$ & $\begin{array}{l}140 \mathrm{mg} \text { every } 2 \\
\text { weeks or } 280 \mathrm{mg} \text {, } \\
350 \mathrm{mg} \text {, or } 420 \mathrm{mg} \\
\text { given every } 4 \text { weeks }\end{array}$ & $\begin{array}{l}\text { Versus ezetimibe } \\
\text { alone: }-26.0 \%(95 \% \\
\mathrm{CI}=-34.1 \% \text { to }-17.9 \%) \\
\text { for } 280 \mathrm{mg} \text { every } 4 \\
\text { weeks to }-38.1 \% \\
\text { (95\% CI }=-43.7 \text { to } \\
-32.4) \text { for } 140 \mathrm{mg} \\
\text { every } 2 \text { weeks } \\
\star \star \\
\text { Combined vs. ezeti- } \\
\text { mibe alone: }-47.3 \% \\
(95 \% \mathrm{CI}=-53.7 \% \\
\text { to }-40.8 \%) \\
\star \star\end{array}$ & NR & $\begin{array}{l}\text { Versus ezetimibe } \\
\text { alone: } 3.6 \%-8.5 \% \\
\star \star \\
\text { Combined vs. } \\
\text { ezetimibe alone: } \star\end{array}$ & $\begin{array}{l}\text { No difference in } \\
\text { overall AEs (63.0\% } \\
\text { vs. } 69.0 \% \text {; pooled } \\
\text { RR }=0.92 ; 95 \% \\
\text { CI }=0.80-1.06) \\
\text { and SAEs (3.0\% } \\
\text { vs. 3.0\%; pooled } \\
\text { RR }=1.04 ; 95 \% \\
\text { CI }=0.34-3.15) \text {. } \\
\text { Significantly lower } \\
\text { WAEs with } \\
\text { evolocumab (3.0\% } \\
\text { vs. } 12.0 \% \text {; pooled } \\
\text { RR=0.29; } 95 \% \\
\text { CI=0.14-0.63). } \star \star \\
\text { No neurocognitive } \\
\text { events and few } \\
\text { injection site } \\
\text { reactions. }\end{array}$ \\
\hline \multicolumn{7}{|c|}{ Varied population versus placebo, with extended follow-up } \\
\hline $\begin{array}{l}2 \text { extensions of } \\
\text { RCTs }^{37} \\
\mathrm{~N}=4,465 \\
12-48 \text { weeks }\end{array}$ & $\begin{array}{l}\text { Usual care (27.3\%). } \\
\text { NR }\end{array}$ & $\begin{array}{l}420 \mathrm{mg} \text { every } \\
4 \text { weeks }\end{array}$ & $\begin{array}{l}\text { Versus placebo: } \\
12 \text { weeks: }-61.0 \% \\
(95 \% \mathrm{CI}=59.0-63.0 \\
P<0.001) \\
\star \star \star\end{array}$ & $\begin{array}{l}12 \text { weeks: LDL goal } \\
<100 \mathrm{mg} / \mathrm{dL}: \\
90.2 \% \text { vs. } 26.0 \% \\
\star \star \star \\
\text { LDL goal }<70 \mathrm{mg} / \mathrm{dL}: \\
73.6 \% \text { vs. } 3.8 \% \\
48 \text { weeks: } 58.4 \% \\
(P<0.001) \\
\star \star\end{array}$ & $\begin{array}{l}12 \text { weeks: } 7.0 \% \\
(P<0.001) \\
\star \star\end{array}$ & $\begin{array}{l}48 \text { weeks: overall } \\
\text { AEs: } 69.2 \% \text { vs. } 64.8 \% \\
(P=0.003) \text {. No } \\
\text { difference in SAEs. } \\
\star \star \\
\star \text { for other harms }\end{array}$ \\
\hline
\end{tabular}

Note: Strength of evidence: $\star \star \star \star \star=$ High; $\star \star \star \star=$ Moderate; $\star \star \star=$ Low; $\star$ =Insufficient

$A E s=$ adverse events; $C I=$ confidence interval; $H D L-C=$ high-density lipoprotein cholesterol; $L D L-C=$ low-density lipoprotein cholesterol; $N R=$ not reported; NSD $=$ no significant difference; $P C S K 9=$ proprotein convertase subtilisin/kexin type 9; $R C T=$ randomized controlled trial; $R R=$ relative risk; SAEs=serious adverse events; WAEs = withdrawal due to adverse events.

strength of evidence (high for lipid outcomes, low to moderate for harms vs. low and insufficient). Additionally, evidence for adjudicated cardiovascular outcomes is low to moderate for alirocumab, showing no differences compared with ezetimibe or placebo, while evidence for evolocumab is insufficient (Table 4). The final population in which both drugs were being studied was a varied cardiovascular risk group that had not met studydefined LDL-C targets while taking risk-appropriate treatment. Here, evolocumab had a much larger study group (1,375 vs. 124), longer trials (52 weeks vs. 10 weeks), and much better strength of evidence (low to high vs. low and insufficient). Of the populations studied with both drugs, this is the one that is least clear on how it fits into step therapy with numerous other antihyperlipidemic drugs available. Evolocumab also has low-strength evidence in patients with homozygous familial hypercholesterolemia and patients deemed intolerant to statin therapy and low- to moderate-strength evidence in broadly varied populations of all of the studied populations but with longer follow-up (Table 4). Homozygous familial hypercholesterolemia is a difficult to treat form of familial hypercholesterolemia, but with evolocumab, patients achieved reductions of $32 \%$ from a mean baseline LDL-C of $348 \mathrm{mg} / \mathrm{dL}$; however, this finding is based on only 50 patients.

Unfortunately, the evidence for the long-term health benefits and harms of the PCSK9 inhibitors alirocumab and evolocumab is insufficient to draw conclusions at this time, mainly because of limited or no information on the long-term impact of the large reductions in LDL-C. The current evidence 
TABLE 4 Cardiovascular Event Outcomes for Alirocumab and Evolocumab

\begin{tabular}{|c|c|c|c|}
\hline $\begin{array}{l}\text { Study, } \mathbf{n} \\
\text { Sample Size } \\
\text { Endpoint for CV Events }\end{array}$ & Treatments & Strength of Evidence & Adjudicated CV Events \\
\hline \multicolumn{4}{|c|}{ High cardiovascular risk (not achieved LDL-C targets $<100 \mathrm{mg} / \mathrm{dL}$ or $<70 \mathrm{mg} / \mathrm{dL}$ ) } \\
\hline $\begin{array}{l}1 \text { RCT }^{27} \\
\text { ODYSSEY COMBO II } \\
\mathrm{N}=720 \\
52 \text { weeks }\end{array}$ & $\begin{array}{l}\text { Alirocumab } 75 \text { to } 150 \mathrm{mg} \text { every } \\
2 \text { weeks + maximal dose statin vs. } \\
\text { ezetimibe } 10 \mathrm{mg}\end{array}$ & $\begin{array}{l}\text { Low. } \\
\text { Downgraded for study limitations, } \\
\text { lack of confirmatory evidence, and } \\
\text { low precision of estimates. }\end{array}$ & $\begin{array}{l}\text { No difference between alirocumab } \\
\text { and ezetimibe ( } 4.8 \% \text { vs. } 3.7 \% \text {; } \\
\text { RR=1.29; } 95 \% \text { CI=0.30-2.74). }\end{array}$ \\
\hline $\begin{array}{l}2 \text { RCTs } 20,30 \\
\text { ODYSSEY COMBO I } \\
\mathrm{N}=2,656 \\
78 \text { weeks }\end{array}$ & $\begin{array}{l}\text { Alirocumab } 75 \text { to } 150 \text { mg every } \\
2 \text { weeks + statin, range of doses } \\
\text { vs. placebo }\end{array}$ & $\begin{array}{l}\text { Moderate. } \\
\text { Downgraded for study limitations } \\
\text { and low precision of estimates. }\end{array}$ & $\begin{array}{l}\text { No difference between alirocumab } \\
\text { and placebo }(2.4 \% \text { vs. } 3.2 \% \text {; pooled } \\
\text { RR }=0.91 ; 95 \% \mathrm{CI}=0.63-1.31) \text {. }\end{array}$ \\
\hline $\begin{array}{l}1 \text { RCT } 29 \\
\text { YUKAWA } \\
\mathrm{N}=310\end{array}$ & $\begin{array}{l}\text { Evolocumab } 70 \text { or } 140 \mathrm{mg} \text { every } \\
2 \text { weeks or } 280 \mathrm{mg} \text { or } 420 \text { mg every } \\
\text { month + moderate-intensity statins } \\
\text { vs. placebo. }\end{array}$ & $\begin{array}{l}\text { Insufficient to draw conclusions. } \\
\text { Downgraded for study limitations, } \\
\text { lack of ability to assess consistency, } \\
\text { and very low precision of estimate. }\end{array}$ & $\begin{array}{l}\text { No difference between evolocumab } \\
\text { and placebo (0/53 with } 420 \mathrm{mg} \\
\text { evolocumab monthly vs. } 1 / 50 \text { with } \\
\text { placebo). }\end{array}$ \\
\hline \multicolumn{4}{|c|}{ Varied population with extended follow-up versus placebo } \\
\hline $\begin{array}{l}\text { Pooled analysis of } 2 \text { extension } \\
\text { studies } 37 \\
N=4,465 \\
48 \text { weeks }\end{array}$ & $\begin{array}{l}\text { Evolocumab } 420 \text { mg every } 4 \text { weeks + } \\
\text { usual care vs. usual care (primarily } \\
\text { statins) }\end{array}$ & $\begin{array}{l}\text { Insufficient to draw conclusions. } \\
\text { Downgraded for study limitations, } \\
\text { lack of ability to assess consistency, } \\
\text { and low precision of estimate. }\end{array}$ & $\begin{array}{l}\text { Lower risk with evolocumab vs. } \\
\text { standard care }(0.95 \% \text { vs. } 2.18 \% \text {; } \\
\mathrm{HR}=0.47 ; 95 \% \mathrm{CI}=0.28-0.78) \text {. } \\
\text { Post hoc analysis limited to MACE: } \\
0.95 \% \text { vs. } 2.11 \%(\mathrm{HR}=0.47 ; 95 \% \\
\mathrm{CI}=0.28-0.78) \text {. }\end{array}$ \\
\hline
\end{tabular}

$C I=$ confidence interval; $C V=$ cardiovascular; $H R=$ hazard ratio; $M A C E=$ composite of death, major coronary events, and major cerebrovascular events; $R C T=$ randomized controlled trial; $R R=$ relative risk.

on health outcomes such as cardiovascular events is limited because these studies reported them as secondary outcomes and were not designed to assess cardiovascular events. This review differs from others because it was limited to the assessment of cardiovascular outcomes that were adjudicated, rather than including cases reported incidentally (Table 4). For evolocumab, the evidence available was insufficient to make any conclusions. For alirocumab, the findings, although of low and moderate strength, did not identify statistically significant differences in high-risk patients compared with placebo or ezetimibe with 52-78 weeks of follow-up. Although these findings are not causational, as hypothesis-generating outcomes, they raise important questions about the long-term benefits of these drugs. As previously noted, we must await the outcome of ongoing trials with predefined cardiovascular endpoints as primary outcomes.

In addition to the uncertainty around long-term outcomes, and with an estimated price of almost $\$ 14,000$ per year, ${ }^{3}$ determining the place these drugs have in the therapy for hypercholesterolemia is critical. Economic modeling may be helpful, but it is limited without evidence of the health outcomes of these drug treatments. A recent economic model, using assumed cardiovascular benefits, found that the cost-effectiveness ratio (cost per quality adjusted life-year [QALY]) was $\$ 681,000$ for those with familial hypercholesterolemia (either type) and $\$ 557,000$ for patients with established cardiovascular disease and LDL-C> $70 \mathrm{mg} / \mathrm{dL} .{ }^{44}$ Although these are estimates for comparison with continuing statins alone, they clearly exceed the typical threshold for cost-effectiveness of $\$ 50,000$ to $\$ 100,000$ per QALY.44 The analyses using this model suggest that in order for the drugs to be cost-effective, the price range should be closer to $\$ 3,600$ per year than the current price range of approximately $\$ 14,000$ per year.

Another important issue raised about this evidence is the comparison groups, including the concomitant antihyperlipidemic therapy given. Clearly, in a step-therapy approach, the choices in the face of inadequate treatment include continuing to maximize the current therapy, add a second treatment, or even switch treatments. Pharmacologically, the PCSK9 inhibitors are likely to work better when used alongside a statin, and most of the studies continue statin therapy in PCSK9 inhibitor-treated patients. A fair comparison, then, would be maximization of the statin therapy (i.e., using high-intensity statins and/or maximally tolerated doses) in the control group in particular. Most of these studies do not adhere to this standard (Tables 2 and 3); consequently, future studies are required to determine the true incremental benefits of PCSK9 inhibitors.

The bulk of the evidence, then, is from patients currently receiving varying doses of statins who have not achieved studyspecified target LDL-C levels. While this less than optimal use of statins is not an ideal comparator as an alternative strategy to PCSK9 inhibitors, it may reflect real-world statin use. When limited to populations of patients who are at high cardiovascular risk and whose baseline LDL-C on statin therapy are 
above targets of $70 \mathrm{mg} / \mathrm{dL}$ to $75 \mathrm{mg} / \mathrm{dL}$ or $<100 \mathrm{mg} / \mathrm{dL}$, we find large absolute reductions in LDL-C and higher proportions of patients achieving these study goals. However, with recent guidelines suggesting that therapy be directed by risk level and not specific LDL-C targets, ${ }^{45}$ and without good-quality evidence on cardiovascular outcomes for the PCSK9 inhibitors, it is less clear how to interpret and apply the findings of these studies. Using the percentage of reduction in LDL-C from baseline is not a better marker, since we do not yet understand the implications of 30\%-60\% above and beyond any initial reductions with a statin. Adding to this lack of clarity, are the several studies in varied- or average-risk populations. In a recent editorial, Shrank et al. (2015) discussed the challenges and implications of determining the best use of PCSK9 inhibitors in light of the recent changes in recommendations for treating hyperlipidemia but recommends a step-approach that promotes maximizing the use of low-cost statin medications rather than PCSK9 inhibitors. ${ }^{14}$

With 2 PCSK9 inhibitors approved and others in the pipeline, there will not only be questions about the role of this new class of drugs in the treatment of hypercholesterolemia, but also comparative questions about whether there are important differences among the drugs. Because these drugs will be taken for many years and are expensive, and because there are still questions regarding long-term benefit and harm, studies in the highest risk populations that are designed to assess cardiovascular and potential harm outcomes with appropriate comparison groups (guideline-recommended statin-intensity level or maximally tolerated high-intensity statins) are needed in order to shed light on these important questions.

\section{Limitations}

The main limitations of this review are those related to the evidence itself, as previously described (e.g., lack of true optimization of statin therapy in control groups). Additional potential limitations of this review include the search strategy and the exclusion of studies published in languages other than English. It was attempted to locate all studies relevant to the scope of this review, but it is possible that evidence was missed. There was limited ability to assess potential publication and reporting bias because of the few opportunities to pool studies and the lack of availability of study protocols. Finally, the scope of this review limited the inclusion of some studies included in other reviews (i.e., comparisons to no treatment) and within those incidentally reported cardiovascular outcomes.

\section{Conclusions}

Alirocumab and evolocumab have evidence of large improvements in lipids and limited evidence on cardiovascular outcomes, but the strength of evidence differs between the drugs. The strength of evidence is greater for alirocumab than evolocumab in patients with high cardiovascular risk not at LDL-C target, while evidence for evolocumab is stronger in patients with heterogeneous familial hypercholesterolemia and patients with varied cardiovascular risk not at LDL-C target. Important questions remain about the comparative effects of either drug on long-term health outcomes.

\section{Authors}

MARIAN MCDONAGH, PharmD; KIM PETERSON, MS; and BRITTANY HOLZHAMMER, MPH, The Pacific Northwest Evidence-based Practice Center, Department of Medical Informatics and Clinical Epidemiology, Oregon Health \& Science University, Portland, Oregon. SERGIO FAZIO, MD, PhD, Center for Preventive Cardiology, Knight Cardiovascular Institute, Oregon Health $\&$ Science University, Portland, Oregon.

AUTHOR CORRESPONDENCE: Marian McDonagh, PharmD, The Pacific Northwest Evidence-based Practice Center, Department of Medical Informatics and Clinical Epidemiology, Oregon Health \& Science University, Mail Code BICC, 3181 S.W. Sam Jackson Park Rd. Portland, OR 97239. Tel.: 503.494.6487;

E-mail: mcdonagh@ohsu.edu.

\section{DISCLOSURES}

This project was funded by The Drug Effectiveness Review Project. Project participants reviewed the manuscript but had no role in conducting the work or writing the manuscript. Any comments received from the participants during the course of the review were taken at the discretion of the authors independently. All authors had access to the data and a role in writing the manuscript. McDonagh, Peterson, and Holzhammer declare no conflict of interest or financial interest in any therapy discussed in this article. Fazio declares receiving compensation from Sanofi for a presentation on his science to a group of their advisors and has served as a consultant to MSD, BASF, NHP, Sanofi, Ionis Pharmaceuticals, and Kowa.

Study concept and design were primarily contributed by McDonagh, along with Peterson and Holzhammer, with assistance from Fazio. Holzhammer took the lead in data collection, with assistance from McDonagh and Peterson. Data interpretation was performed by McDonagh, Peterson, and Fazio. The manuscript was written by McDonagh, Peterson, and Fazio, with assistance from Holzhammer, and revised by all the authors.

\section{ACKNOWLEDGMENTS}

The authors thank Ryan Stoner, MA, and Laura LaLonde, BS, for their assistance with retrieval of articles, bibliographic work, and data abstraction.

\section{REFERENCES}

1. Expert Panel on Detection, Evaluation, and Treatment of High Blood Cholesterol in Adults. Executive summary of the third report of the National Cholesterol Education Program (NCEP) Expert Panel on Detection, Evaluation, and Treatment of High Blood Cholesterol in Adults (Adult Treatment Panel III). JAMA. 2001;285(19):2486-97.

2. Cholesterol Treatment Trialists' (CTT) Collaborators, Mihaylova B, Emberson J, et al. The effects of lowering LDL cholesterol with statin therapy in people at low risk of vascular disease: meta-analysis of individual data from 27 randomised trials. Lancet. 2012;380(9841):581-90. 
3. Evolocumab (Repatha) — a second PCSK9 inhibitor to lower LDLcholesterol. JAMA. 2015;314(21):2298-99.

4. Carroll J. UPDATED: Amgen gets a big win with FDA OK for PCSK9 cholesterol drug Repatha. FierceBiotech. August 27, 2015. Available at: http://www.fiercebiotech.com/story/amgen-gets-big-win-fda-ok-pcsk9-drugrepatha/2015-08-27. Accessed April 12, 2016.

5. Pollack A. New drug sharply lowers cholesterol, but it's costly. The New York Times. July 24, 2015. Available at: http://www.nytimes.com/2015/07/25/ business/us-approves-drug-that-can-sharply-lower-cholesterol-levels. html?ref=health. Accessed April 12, 2016.

6. Staton T. Payers fret about the next drug doomsday: pricey PCSK9 cholesterol meds. FiercePharmaMarketing. May 7, 2014. Available at: http://www. fiercepharmamarketing.com/story/payers-already-fretting-about-next-pharmapocalypse-pricey-pcsk9-cholestero/2014-05-07. Accessed April 12, 2016.

7. Navarese EP, Kołodziejczak M, Schulze V, et al. Effects of proprotein convertase subtilisin/kexin type 9 antibodies in adults with hypercholesterolemia: a systematic review and meta-analysis. Ann Intern Med. 2015;163(1):40-51.

8. Zhang XL, Zhu QQ, Zhu L, et al. Safety and efficacy of anti-PCSK9 antibodies: a meta-analysis of 25 randomized, controlled trials. BMC Med. 2015;13:123.

9. Liakos A, Athanasiadou E, Mainou M, et al. Effects of proprotein convertase subtilisin/kexin type 9 antibodies in adults with hypercholesterolemia [editorial]. Ann Intern Med. 2015;163(3):241.

10. Battaggia A, Donzelli A, Font M. Effects of proprotein convertase subtili$\sin /$ kexin type 9 antibodies in adults with hypercholesterolemia [editorial]. Ann Intern Med. 2015;163(3):241-42.

11. Auer J, Berent R, Primus C. PCSK9 inhibitors and cardiovascular events [editorial]. N Engl J Med. 2015;373(8):773.

12. Goemann IM, Londero TM, Dora JM. PCSK9 inhibitors and cardiovascular events [editorial]. N Engl J Med. 2015;373(8):773-74.

13. Giugliano RP, Sabatine MS. Are PCSK9 inhibitors the next breakthrough in the cardiovascular field? J Am Coll Cardiol. 2015;65(24):2638-51.

14. Shrank WH, Barlow JF, Brennan TA. New therapies in the treatment of high cholesterol: an argument to return to goal-based lipid guidelines. JAMA. 2015;314(14):1443-44.

15. Pfizer. The evaluation of bococizumab (PF-04950615; RN316) in reducing the occurrence of major cardiovascular events in high risk subjects (SPIRE-1). ClinicalTrials.gov Identifier NCT01975376. March 2016. Available at: https://clinicaltrials.gov/ct2/show/NCT01975376?term=NCT01975376\&ra nk=1. Accessed April 12, 2016.

16. Pfizer. The evaluation of bococizumab (PF-04950615; RN316) in reducing the occurrence of major cardiovascular events in high risk subjects (SPIRE-2). ClinicalTrials.gov Identifier NCT01975389. March 2016. Available at: https://clinicaltrials.gov/ct2/show/NCT01975389?term=NCT01975389\&r ank=1. Accessed April 12, 2016.

17. Sanofi. ODYSSEY outcomes: evaluation of cardiovascular outcomes after an acute coronary syndrome during treatment with alirocumab SAR236553 (REGN727). ClinicalTrials.gov Identifier NCT01663402. April 2016. Available at: https://clinicaltrials.gov/ct2/show/NCT01663402?term=NCT016 63402\&rank=1. Accessed April 12, 2016.

18. Amgen. Further cardiovascular outcomes research with PCSK9 Inhibition in subjects with elevated risk (FOURIER). ClinicalTrials.gov Identifier NCT01764633. January 2016. Available at: https://clinicaltrials. gov/ct2/show/NCT01764633?term=NCT01764633\&rank=1. Accessed April 12, 2016.

19. Chambers JD, Chenoweth M, Cangelosi MJ, Pyo J, Cohen JT, Neumann PJ. Medicare is scrutinizing evidence more tightly for national coverage determinations. Health Aff (Millwood). 2015;34(2):253-60.
20. Robinson JG, Farnier M, Krempf M, et al. Efficacy and safety of alirocumab in reducing lipids and cardiovascular events. N Engl J Med. 2015;372(16):1489-99.

21. Robinson JG, Kastelein JJ. PCSK9 inhibitors and cardiovascular events [editorial]. N Engl J Med. 2015;373(8):774.

22. Center for Evidence-based Policy. Drug Effectiveness Review Project (DERP). Oregon Health \& Science University. Available at: http://www.ohsu. edu/xd/research/centers-institutes/evidence-based-policy-center/evidence/ derp/index.cfm. Accessed April 12, 2016.

23. McDonagh MS, Jonas DE, Gartlehner G, et al. Methods for the Drug Effectiveness Review Project. BMC Med Res Methodol. 2012;12:140.

24. Higgins JP, Thompson SG, Deeks JJ, Altman DG. Measuring inconsistency in meta-analyses. BMJ. 2003;327(7414):557-60.

25. Berkman N, Lohr K, Ansari M, et al. Grading the strength of a body of evidence when assessing health care interventions for the effective health care program of the Agency for Healthcare Research and Quality: an update. Methods Guide for Comparative Effectiveness Reviews. (Prepared by the RTI-UNC Evidence-based Practice Center under Contract No. 290-200710056-I). AHRQ Publication No. 13(14)-EHC130-EF. Rockville, MD: Agency for Healthcare Research and Quality. November 2013. Available at: https:// www.effectivehealthcare.ahrq.gov/ehc/products/457/1752/methods-guidance-grading-evidence-131118.pdf. Accessed April 12, 2016.

26. Blom DJ, Hala T, Bolognese M, et al. A 52-week placebo-controlled trial of evolocumab in hyperlipidemia. N Engl J Med. 2014;370(19):1809-19.

27. Cannon CP, Cariou B, Blom D, et al. Efficacy and safety of alirocumab in high cardiovascular risk patients with inadequately controlled hypercholesterolaemia on maximally tolerated doses of statins: the ODYSSEY COMBO II randomized controlled trial. Eur Heart J. 2015;36(19):1186-94.

28. Giugliano RP, Desai NR, Kohli P, et al. Efficacy, safety, and tolerability of a monoclonal antibody to proprotein convertase subtilisin/kexin type 9 in combination with a statin in patients with hypercholesterolaemia (LAPLACE-TIMI 57): a randomised, placebo-controlled, dose-ranging, phase 2 study. Lancet. 2012;380(9858):2007-17.

29. Hirayama A, Honarpour N, Yoshida M, et al. Effects of evolocumab (AMG 145), a monoclonal antibody to PCSK9, in hypercholesterolemic, statin-treated Japanese patients at high cardiovascular risk-primary results from the phase 2 YUKAWA study. Circ J. 2014;78(5):1073-82.

30. Kereiakes DJ, Robinson JG, Cannon CP, et al. Efficacy and safety of the proprotein convertase subtilisin/kexin type 9 inhibitor alirocumab among high cardiovascular risk patients on maximally tolerated statin therapy: The ODYSSEY COMBO I study. Am Heart J. 2015;169(6):906-15.

31. McKenney JM, Koren MJ, Kereiakes DJ, Hanotin C, Ferrand A-C, Stein EA. Safety and efficacy of a monoclonal antibody to proprotein convertase subtilisin/kexin type 9 serine protease, SAR236553/REGN727, in patients with primary hypercholesterolemia receiving ongoing stable atorvastatin therapy. J Am Coll Cardiol. 2012;59(25):2344-53.

32. Raal F, Scott R, Somaratne R, et al. Low-density lipoprotein cholesterol-lowering effects of AMG 145, a monoclonal antibody to proprotein convertase subtilisin/kexin type 9 serine protease in patients with heterozygous familial hypercholesterolemia: the Reduction of LDL-C with PCSK9 Inhibition in Heterozygous Familial Hypercholesterolemia Disorder (RUTHERFORD) randomized trial. Circulation. 2012;126(20):2408-17.

33. Raal FJ, Honarpour N, Blom DJ, et al. Inhibition of PCSK9 with evolocumab in homozygous familial hypercholesterolaemia (TESLA Part B): a randomised, double-blind, placebo-controlled trial. Lancet. 2015;385(9965):341-50.

34. Raal FJ, Stein EA, Dufour R, et al. PCSK9 inhibition with evolocumab (AMG 145) in heterozygous familial hypercholesterolaemia (RUTHERFORD-2): a randomised, double-blind, placebo-controlled trial. Lancet. 2015;385(9965):331-40. 
35. Robinson JG, Nedergaard BS, Rogers WJ, et al. Effect of evolocumab or ezetimibe added to moderate- or high-intensity statin therapy on LDL-C lowering in patients with hypercholesterolemia: the LAPLACE-2 randomized clinical trial. JAMA. 2014;311(18):1870-82.

36. Roth EM, McKenney JM, Hanotin C, Asset G, Stein EA. Atorvastatin with or without an antibody to PCSK9 in primary hypercholesterolemia. N Engl J Med. 2012;367(20):1891-900.

37. Sabatine MS, Giugliano RP, Wiviott SD, et al. Efficacy and safety of evolocumab in reducing lipids and cardiovascular events. N Engl J Med. 2015;372(16):1500-09.

38. Stein EA, Gipe D, Bergeron J, et al. Effect of a monoclonal antibody to PCSK9, REGN727/SAR236553, to reduce low-density lipoprotein cholesterol in patients with heterozygous familial hypercholesterolaemia on stable statin dose with or without ezetimibe therapy: a phase 2 randomised controlled trial. Lancet. 2012;380(9836):29-36.

39. Stein EA, Mellis S, Yancopoulos GD, et al. Effect of a monoclonal antibody to PCSK9 on LDL cholesterol. N Engl J Med. 2012;366(12):1108-18.

40. Stroes E, Colquhoun D, Sullivan D, et al. Anti-PCSK9 antibody effectively lowers cholesterol in patients with statin intolerance: the GAUSS-2 randomized, placebo-controlled phase 3 clinical trial of evolocumab. J Am Coll Cardiol. 2014;63(23):2541-48

41. Sullivan D, Olsson AG, Scott R, et al. Effect of a monoclonal antibody to PCSK9 on low-density lipoprotein cholesterol levels in statin-intolerant patients: the GAUSS randomized trial. JAMA. 2012;308(23):2497-506.
42. Koren MJ, Blom D, Giugliano RP, et al. Safety and tolerability of very low LDL-C levels in patients treated with 52 weeks of evolocumab (AMG 145). Circulation. 2014;130(Suppl 2):Al6865. [Abstract 16865]

43. Desai NR, Giugliano RP, Zhou J, et al. AMG 145, a monoclonal antibody against PCSK9, facilitates achievement of national cholesterol education program-adult treatment panel III low-density lipoprotein cholesterol goals among high-risk patients: an analysis from the LAPLACE-TIMI 57 trial (LDL-C assessment with PCSK9 monoclonal antibody inhibition combined with statin thErapy-thrombolysis in myocardial infarction 57). J Am Coll Cardiol. 2014;63(5):430-33.

44. Tice JA, Ollendorf DA, Cunningham C, et al. PCSK9 inhibitors for treatment of high cholesterol: effectiveness, value, and value-based price benchmarks: draft report. A technology assessment. Institute for Clinical and Economic Review. September 8, 2015. Available at: http://icer-review.org/ wp-content/uploads/2015/04/PCSK9_Draft_Report_0908151.pdf. Accessed April 12, 2016.

45. Stone NJ, Robinson JG, Lichtenstein AH, et al. 2013 ACC/AHA guideline on the treatment of blood cholesterol to reduce atherosclerotic cardiovascular risk in adults: a report of the American College of Cardiology/ American Heart Association Task Force on Practice Guidelines. Circulation. 2014;129(25 Suppl 2):S1-45.

46. Liberati A, Altman DG, Tetzlaff J. The PRISMA statement for reporting systematic reviews and meta-analyses of studies that evaluate health care interventions: explanation and elaboration. J Clin Epidemiol. 2009;62(10):el-34. 


\section{APPENDIX A Quality Assessment of Randomized Controlled Trials of Alirocumab and Evolocumab}

\begin{tabular}{|c|c|c|c|c|c|}
\hline $\begin{array}{l}\text { Author, Year } \\
\text { Study Name }\end{array}$ & $\begin{array}{l}\text { Randomization } \\
\text { Adequate? }\end{array}$ & $\begin{array}{c}\text { Allocation Concealment } \\
\text { Adequate? }\end{array}$ & $\begin{array}{l}\text { Groups Similar at } \\
\text { Baseline? }\end{array}$ & $\begin{array}{l}\text { Outcome Assessors } \\
\text { Blinded? }\end{array}$ & Clinician Blinded? \\
\hline \multicolumn{6}{|l|}{ Alirocumab } \\
\hline Cannon, $2015^{1}$ & Yes & Yes, IVRS & Yes & $\begin{array}{l}\text { Unclear; outcome } \\
\text { assessors not } \\
\text { explicitly noted }\end{array}$ & $\begin{array}{l}\text { Yes; double-blind, } \\
\text { double dummy }\end{array}$ \\
\hline Kereiakes, $2015^{2}$ & Unclear & Unclear & $\begin{array}{l}\text { Unclear; fewer males } \\
\text { ( } 63 \% \text { vs } 72 \% \text { ) and less } \\
\text { other lipid-lowering } \\
\text { therapy use ( } 38 \% \text { vs. } \\
49 \% \text { ) in alirocumab } \\
\text { group }\end{array}$ & Unclear & Yes \\
\hline McKenney, 20123 & Unclear & Unclear & $\begin{array}{l}\text { Some differences in \% } \\
\text { white, \% with diabetes, } \\
\text { hypertension, smokers; } \\
\text { lipid values similar at } \\
\text { baseline }\end{array}$ & Unclear & Unclear \\
\hline $\begin{array}{l}\text { Robinson, } 2015^{4} \\
\text { ODYSSEY }\end{array}$ & Yes & Yes & Yes & Yes & Yes \\
\hline Roth, $2012^{5}$ & Yes, computer-generated & Yes, IVRS & $\begin{array}{l}\text { No; the placebo group } \\
\text { had fewer patients }>65 \\
\text { y, fewer white patients, } \\
\text { and more with diabetes }\end{array}$ & Yes & Yes \\
\hline Stein, $2012^{6}$ & Yes, IVRS & Yes, IVRS & $\begin{array}{l}\text { Some differences in \% } \\
\text { male ( } 47 \% \text { to } 81 \%) \text { and } \\
\text { CAD }(25 \% \text { to } 53 \%)\end{array}$ & Yes & Yes \\
\hline Stein, $2012^{7}$ & Unclear & $\begin{array}{l}\text { Yes, using an electronic } \\
\text { data capture tool }\end{array}$ & $\begin{array}{l}\text { Some differences in age, } \\
\text { sex, race, baseline statin } \\
\text { use, but lipid values } \\
\text { similar }\end{array}$ & Yes & Yes \\
\hline \multicolumn{6}{|l|}{ Evolocumab } \\
\hline $\begin{array}{l}\text { Blom, } 20148 \\
\text { DESCARTES }\end{array}$ & $\begin{array}{l}\text { Yes, stratified by } \\
\text { background therapy }\end{array}$ & Yes, IVRS & Yes & Yes & Yes \\
\hline $\begin{array}{l}\text { Giugliano, } 2012^{9} \\
\text { Desai, 201410 } \\
\text { LAPLACE-TIMI } 57\end{array}$ & Yes, computer-generated & Yes, IVRS & $\begin{array}{l}\text { Some differences in \% } \\
\text { female (range } 32 \% \text { to } \\
54 \% \text { ), \% white (range } \\
81 \% \text { to } 92 \% \text { ), \% with } \\
\text { diabetes (range } 11 \% \text { to } \\
24 \% \text { ), etc. No difference } \\
\text { in baseline lipid values, } \\
\text { statin use }\end{array}$ & Yes for lipid outcomes & Yes for lipid outcomes \\
\hline $\begin{array}{l}\text { Hirayama, } 201411 \\
\text { YUKAWA }\end{array}$ & Unclear & Unclear & $\begin{array}{l}\text { Unclear; in evolocumab } \\
\text { groups, higher } \% \text { female } \\
\text { (32\% to } 49 \% \text { vs. } 29 \% \text { to } \\
31 \% \text { ), higher T2DM } \\
\text { ( } 34 \% \text { to } 49 \%), \geq 2 \text { CV } \\
\text { risk factors }(48 \% \text { to } 65 \% \\
\text { vs. } 46 \% \text { to } 52 \% \text { ) }\end{array}$ & Unclear & $\begin{array}{l}\text { Yes to dose, but not } \\
\text { frequency }\end{array}$ \\
\hline $\begin{array}{l}\text { Author, Year } \\
\text { Study Name }\end{array}$ & Patient Blinded? & Intention to Treat? & $\begin{array}{c}\text { Acceptable Level } \\
\text { of Overall } \\
\text { Attrition }(\leq 20 \%) ?\end{array}$ & $\begin{array}{l}\text { Acceptable Level } \\
\text { of Differential } \\
\text { Attrition }(<10 \%) \text { ? }\end{array}$ & Overall Quality \\
\hline \multicolumn{6}{|l|}{ Alirocumab } \\
\hline Cannon, $2015^{1}$ & $\begin{array}{l}\text { Yes, double-blind, } \\
\text { double dummy }\end{array}$ & Yes & Yes & Yes & Good \\
\hline Kereiakes, $2015^{2}$ & Yes & Yes & Yes; $26 \%$ for 52 weeks & Yes & Fair \\
\hline McKenney, $2012^{3}$ & Unclear & Yes & Yes & Yes & Fair \\
\hline $\begin{array}{l}\text { Robinson, } 2015^{4} \\
\text { ODYSSEY }\end{array}$ & Yes & No & Yes & Yes & Good \\
\hline Roth, $2012^{5}$ & Yes & Yes & Yes & $\begin{array}{l}\text { Yes, except at visit } 16 \\
\text { ( } 28 \% \text { missing from pla- } \\
\text { cebo group vs. } 17 \% \text { and } \\
11 \% \text { in active groups) }\end{array}$ & Fair \\
\hline Stein, $2012^{6}$ & Yes & Yes & $\begin{array}{l}\text { Yes, only } 1 \text { patient } \\
\text { discontinued }\end{array}$ & Yes & Fair \\
\hline Stein, $2012^{7}$ & Yes & Yes & Yes & Yes & Fair \\
\hline
\end{tabular}


APPENDIX A Quality Assessment of Randomized Controlled Trials of Alirocumab and Evolocumab (continued)

\begin{tabular}{|c|c|c|c|c|c|}
\hline \multicolumn{6}{|l|}{ Evolocumab } \\
\hline $\begin{array}{l}\text { Blom, } 20148 \\
\text { DESCARTES }\end{array}$ & Yes & Yes & Yes & Yes & Good \\
\hline $\begin{array}{l}\text { Giugliano, } 2012^{9} \\
\text { Desai, 201410 } \\
\text { LAPLACE-TIMI } 57\end{array}$ & Yes & $\begin{array}{l}\text { Yes, some with small } \\
\text { numbers missing } \\
\text { but }<5 \%\end{array}$ & Yes & Yes & Good \\
\hline $\begin{array}{l}\text { Hirayama, } 201411 \\
\text { YUKAWA }\end{array}$ & $\begin{array}{l}\text { Yes to dose, but not } \\
\text { frequency }\end{array}$ & Yes & Yes & Yes & Fair \\
\hline $\begin{array}{l}\text { Author, Year } \\
\text { Study Name }\end{array}$ & $\begin{array}{l}\text { Randomization } \\
\text { Adequate? }\end{array}$ & $\begin{array}{c}\text { Allocation Concealment } \\
\text { Adequate? }\end{array}$ & $\begin{array}{l}\text { Groups Similar at } \\
\text { Baseline? }\end{array}$ & $\begin{array}{l}\text { Outcome Assessors } \\
\text { Blinded? }\end{array}$ & Clinician Blinded? \\
\hline $\begin{array}{l}\text { Raal, } 2012^{12} \\
\text { RUTHERFORD }\end{array}$ & Yes, IVRS & Yes, IVRS & $\begin{array}{l}\text { Unclear; \% male ranged } \\
\text { from } 42.9 \% \text { to } 62.5 \%\end{array}$ & $\begin{array}{l}\text { Unclear; lipid analysis } \\
\text { performed by central } \\
\text { lab; blinding NR }\end{array}$ & $\begin{array}{l}\text { Unclear; described as } \\
\text { double-blind; full study } \\
\text { team blinded to lab } \\
\text { values; but treatment } \\
\text { appearance NR }\end{array}$ \\
\hline $\begin{array}{l}\text { Raal, } 2015^{13} \\
\text { RUTHERFORD-2 }\end{array}$ & Yes, computer-generated & Yes, IVRS & $\begin{array}{l}\text { Unclear; CAD ranged } \\
\text { from } 18 \% \text { to } 35 \%\end{array}$ & $\begin{array}{l}\text { Yes; patients, study } \\
\text { personnel, investigators, } \\
\text { and Amgen study staff } \\
\text { masked to treatment } \\
\text { assignments within } \\
\text { dosing groups; masking } \\
\text { achieved by identical } \\
\text { look of autoinjector pens } \\
\text { containing study drug } \\
\text { (evolocumab) or placebo }\end{array}$ & Yes \\
\hline $\begin{array}{l}\text { Raal, } 2015^{14} \\
\text { TESLA Part B }\end{array}$ & $\begin{array}{l}\text { Yes, computer-generated, } \\
\text { stratified by LDL-C at } \\
\text { screening and } \\
\text { implemented by } \\
\text { computerized IVRS }\end{array}$ & Yes; IVRS & $\begin{array}{l}\text { Yes; groups differ } \\
\text { slightly by ethnicity and } \\
\text { clinically evident CAD } \\
\text { but are similar for other } \\
\text { baseline characteristics }\end{array}$ & Yes & Yes \\
\hline Robinson, 201415 & Unclear & Unclear & $\begin{array}{l}\text { Some differences in } \\
\text { female sex }(22 \% \text { to } \\
59 \%) \text {, CAD ( } 7 \% \text { to } 36 \%)\end{array}$ & Yes & Yes \\
\hline $\begin{array}{l}\text { Sabatine, } 2015^{16} \\
\text { OSLER-1 and OSLER-2 }\end{array}$ & Yes & Yes & Yes & No & No \\
\hline $\begin{array}{l}\text { Stroes, } 201417 \\
\text { GAUSS-2 }\end{array}$ & Unclear & Unclear & $\begin{array}{l}\text { Some differences in \# } \\
\text { of intolerable statins (\% } \\
\text { patients with } 2=33 \% \\
\text { to } 49 \% \text { ), diabetes ( } 15 \% \\
\text { to } 31 \% \text { ), hypertension } \\
(55 \% \text { to } 75 \% \text { ), but simi- } \\
\text { lar LDL and HDL }\end{array}$ & Yes & Yes \\
\hline $\begin{array}{l}\text { Sullivan, } 2012^{18} \\
\text { GAUSS }\end{array}$ & Unclear & Yes, IVRS & $\begin{array}{l}\text { Some differences in \% } \\
\text { female (range } 56 \% \text { to } \\
77 \% \text { ), \% white ( } 80 \% \\
\text { to } 94 \% \text { ), \# of previous } \\
\text { statin intolerances, but } \\
\text { similar LDL and HDL }\end{array}$ & $\begin{array}{l}\text { No for ezetimibe; } \\
\text { unclear for evolocumab }\end{array}$ & $\begin{array}{l}\text { No for ezetimibe; } \\
\text { unclear for evolocumab }\end{array}$ \\
\hline $\begin{array}{l}\text { Author, Year } \\
\text { Study Name }\end{array}$ & Patient Blinded? & Intention to Treat? & $\begin{array}{l}\text { Acceptable Level of } \\
\text { Overall Attrition } \\
(\leq 20 \%) ?\end{array}$ & $\begin{array}{c}\text { Acceptable Level of } \\
\text { Differential Attrition } \\
(<10 \%) ?\end{array}$ & Overall Quality \\
\hline $\begin{array}{l}\text { Raal, } 2012^{12} \\
\text { RUTHERFORD }\end{array}$ & $\begin{array}{l}\text { Unclear; described as } \\
\text { double-blind; full study } \\
\text { team blinded to lab } \\
\text { values; but treatment } \\
\text { appearance NR }\end{array}$ & Yes & Yes & Yes & Fair \\
\hline $\begin{array}{l}\text { Raal, } 2015^{13} \\
\text { RUTHERFORD-2 }\end{array}$ & Yes & Yes & Yes & Yes & Good \\
\hline $\begin{array}{l}\text { Raal, } 2015^{14} \\
\text { TESLA Part B }\end{array}$ & Yes & Yes & Yes & Yes & Good \\
\hline Robinson, $2014^{15}$ & Yes & Yes & Yes & No; range, $2 \%$ to $25 \%$ & Fair \\
\hline $\begin{array}{l}\text { Sabatine, } 2015^{16} \\
\text { OSLER-1 and OSLER-2 }\end{array}$ & No & Yes & Yes & Yes & Fair \\
\hline
\end{tabular}


APPENDIX A Quality Assessment of Randomized Controlled Trials of Alirocumab and Evolocumab (continued)

\begin{tabular}{l|c|c|c|c}
\hline $\begin{array}{l}\text { Author, Year } \\
\text { Study Name }\end{array}$ & Patient Blinded? & Intention to Treat? & $\begin{array}{c}\text { Acceptable Level of } \\
\text { Overall Attrition } \\
(\leq 20 \%) ?\end{array}$ & $\begin{array}{c}\text { Acceptable Level of } \\
\text { Differential Attrition } \\
(<10 \%) ?\end{array}$ \\
\hline $\begin{array}{l}\text { Stroes, 201417 } \\
\text { GAUSS-2 }\end{array}$ & Yes & Yes & Yes & Yes \\
\hline $\begin{array}{l}\text { Sullivan, 2012 } \\
\text { GAUSS }\end{array}$ & $\begin{array}{l}\text { No for ezetimibe; } \\
\text { unclear for evolocumab }\end{array}$ & Yes & Yes & Yes \\
\hline
\end{tabular}

Note: Numbered footnotes refer to citations in the References at the end of the appendices.

$C A D=$ coronary artery disease; $C V=$ cardiovascular; $H D L=$ high-density lipoprotein; IVRS = interactive voice response system; LDL-C=low-density lipoprotein cholesterol; NR= not reported; $T 2 D M=$ type 2 diabetes mellitus. 


\section{APPENDIX B Strength of Evidence}

\begin{tabular}{|c|c|c|c|c|c|c|c|c|}
\hline $\begin{array}{l}\text { Strength of } \\
\text { Evidence Grade }\end{array}$ & $\begin{array}{l}\text { Study Design; } \\
\text { No. Studies (N) }\end{array}$ & $\begin{array}{c}\text { Study } \\
\text { Limitations }\end{array}$ & Directness & Consistency & Precision & $\begin{array}{l}\text { Reporting } \\
\text { Bias }\end{array}$ & Other Issues & Finding \\
\hline \multicolumn{9}{|c|}{ Key Question 1. Heterozygous Familial Hypercholesterolemia } \\
\hline \multicolumn{9}{|c|}{ Alirocumab vs. placebo $\times 6$ weeks in patients taking atorvastatin $10 \mathrm{mg}-40 \mathrm{mg}^{7}$} \\
\hline \multicolumn{9}{|c|}{ LDL-C lowering ability } \\
\hline $\begin{array}{l}\text { LDL-C: } \\
\text { Insufficient }\end{array}$ & $1 \mathrm{RCT}, \mathrm{N}=21$ & Medium & Direct & Unknown & Imprecise & Undetected & None & $\begin{array}{l}\text { No conclusion; range } \\
\text { in difference in percent } \\
\text { change from baseline } \\
\text { vs. placebo ( } \% \text { points): } \\
-41.4 \% \text { to }-55.7 \% \\
\end{array}$ \\
\hline \multicolumn{9}{|c|}{ HDL-C raising ability } \\
\hline $\begin{array}{l}\text { HDL-C: } \\
\text { Insufficient }\end{array}$ & $1 \mathrm{RCT}, \mathrm{N}=21$ & Medium & Direct & Unknown & Imprecise & Undetected & None & $\begin{array}{l}\text { No conclusion; sig- } \\
\text { nificant difference in } \\
\% \text { change from base- } \\
\text { line for } 50 \mathrm{mg} \text { or } 100 \\
\text { mg dose, but greater } \\
\text { increase for } 150 \mathrm{mg} \\
\text { vs. placebo }=23.0 \% \\
(P=0.033)\end{array}$ \\
\hline \multicolumn{9}{|c|}{ Overall adverse events } \\
\hline $\begin{array}{l}\text { Overall AE: } \\
\text { Insufficient }\end{array}$ & $1 \mathrm{RCT}, \mathrm{N}=21$ & Medium & Direct & Unknown & Imprecise & Undetected & None & $\begin{array}{l}\text { Greater only for } 150 \\
\text { mg dose: } 80 \% \text { vs. } \\
0 \% \text {; EPC-calculated } \\
P=0.015\end{array}$ \\
\hline \multicolumn{9}{|c|}{ Withdrawals due to adverse events } \\
\hline $\begin{array}{l}\text { AE withdrawal: } \\
\text { Insufficient }\end{array}$ & $1 \mathrm{RCT}, \mathrm{N}=21$ & Medium & Direct & Unknown & Imprecise & Undetected & None & $\begin{array}{l}\text { No difference; no } \\
\text { events }\end{array}$ \\
\hline \multicolumn{9}{|c|}{ Serious adverse events } \\
\hline $\begin{array}{l}\text { Serious AE: } \\
\text { Insufficient }\end{array}$ & $1 \mathrm{RCT}, \mathrm{N}=21$ & Medium & Direct & Unknown & Imprecise & Undetected & None & $\begin{array}{l}\text { No difference; no } \\
\text { events }\end{array}$ \\
\hline \multicolumn{9}{|c|}{ Specific adverse events: neurocognitive events } \\
\hline $\begin{array}{l}\text { Neurocognitive } \\
\text { dysfunction: } \\
\text { Insufficient }\end{array}$ & $1 \mathrm{RCT}, \mathrm{N}=21$ & Medium & Direct & Unknown & Imprecise & Undetected & None & $\begin{array}{l}\text { No difference; no } \\
\text { events }\end{array}$ \\
\hline \multicolumn{9}{|c|}{ Specific adverse events: injection site } \\
\hline $\begin{array}{l}\text { Injection site } \\
\text { erythema: } \\
\text { Insufficient }\end{array}$ & $1 \mathrm{RCT}, \mathrm{N}=21$ & Medium & Direct & Unknown & Imprecise & Undetected & None & $\begin{array}{l}\text { No difference; no } \\
\text { events }\end{array}$ \\
\hline \multicolumn{9}{|c|}{ Alirocumab vs. placebo $\times 12$ weeks in patients taking mixed max statin plus ezetimibe 6} \\
\hline \multicolumn{9}{|c|}{ LDL-C lowering ability } \\
\hline LDL-C: Low & $1 \mathrm{RCT}, \mathrm{N}=77$ & Medium & Direct & Unknown & Imprecise & Undetected & None & $\begin{array}{l}\text { Greater reduction; } \\
\text { range in absolute dif- } \\
\text { ference in percent } \\
\text { change from baseline } \\
\text { vs. placebo (\% points): } \\
-18 \% \text { to }-57 \%\end{array}$ \\
\hline \multicolumn{9}{|c|}{ HDL-C raising ability } \\
\hline HDL-C: Low & $1 \mathrm{RCT}, \mathrm{N}=77$ & Medium & Direct & Unknown & Imprecise & Undetected & None & $\begin{array}{l}\text { No significant differ- } \\
\text { ence in \% change from } \\
\text { baseline except for } \\
150 \text { mg every } 2 \text { weeks: } \\
+12.34 \% \text { vs. }+2.20 \% \text {; } \\
P=0.050\end{array}$ \\
\hline \multicolumn{9}{|c|}{ Overall adverse events } \\
\hline $\begin{array}{l}\text { Overall AE: } \\
\text { Insufficient }\end{array}$ & $1 \mathrm{RCT}, \mathrm{N}=77$ & Medium & Direct & Unknown & Imprecise & Undetected & None & $\begin{array}{l}\text { No difference: } 75 \% \text { to } \\
87 \% \text { for alirocumab vs. } \\
60 \% \text { for placebo }\end{array}$ \\
\hline
\end{tabular}




\section{APPENDIX B Strength of Evidence (continued)}

\begin{tabular}{|c|c|c|c|c|c|c|c|c|}
\hline $\begin{array}{l}\text { Strength of } \\
\text { Evidence Grade }\end{array}$ & $\begin{array}{l}\text { Study Design; } \\
\text { No. Studies (N) }\end{array}$ & $\begin{array}{c}\text { Study } \\
\text { Limitations }\end{array}$ & Directness & Consistency & Precision & $\begin{array}{l}\text { Reporting } \\
\text { Bias }\end{array}$ & Other Issues & Finding \\
\hline \multicolumn{9}{|c|}{ Withdrawals due to adverse events } \\
\hline $\begin{array}{l}\text { AE withdrawal: } \\
\text { Insufficient }\end{array}$ & $1 \mathrm{RCT}, \mathrm{N}=77$ & Medium & Direct & Unknown & Imprecise & Undetected & None & $\begin{array}{l}\text { No difference; only } 1 \\
\text { patient taking } \\
\text { alirocumab } 300 \mathrm{mg} \\
\text { every } 4 \text { weeks }\end{array}$ \\
\hline \multicolumn{9}{|c|}{ Serious adverse events } \\
\hline $\begin{array}{l}\text { Serious AE: } \\
\text { Insufficient }\end{array}$ & $1 \mathrm{RCT}, \mathrm{N}=77$ & Medium & Direct & Unknown & Imprecise & Undetected & None & $\begin{array}{l}\text { No difference; only } 1 \\
\text { patient in the placebo } \\
\text { group with GI disorder }\end{array}$ \\
\hline \multicolumn{9}{|c|}{ Specific adverse events: neurocognitive events } \\
\hline $\begin{array}{l}\text { Neurocognitive } \\
\text { dysfunction: } \\
\text { Insufficient }\end{array}$ & $1 \mathrm{RCT}, \mathrm{N}=77$ & Medium & Direct & Unknown & Imprecise & Undetected & None & $\begin{array}{l}\text { No difference; } \\
\text { no events }\end{array}$ \\
\hline \multicolumn{9}{|c|}{ Specific adverse events: injection site } \\
\hline $\begin{array}{l}\text { Injection site } \\
\text { reactions: } \\
\text { Insufficient }\end{array}$ & $1 \mathrm{RCT}, \mathrm{N}=77$ & Medium & Direct & Unknown & Imprecise & Undetected & None & $\begin{array}{l}\text { No difference; } 27 \% \text { to } \\
47 \% \text { vs. } 13 \%\end{array}$ \\
\hline \multicolumn{9}{|c|}{ Evolocumab vs. placebo $\times 12$ weeks in patients taking high-intensity statins+ezetimibe (RUTHERFORD 1 and 2$)^{12,13}$} \\
\hline \multicolumn{9}{|c|}{ LDL-C lowering ability } \\
\hline LDL-C: High & 2 RCTs, $N=499$ & Low & Direct & Consistent & Precise & Undetected & None & $\begin{array}{l}\text { Greater reductions for } \\
\text { evolocumab: absolute } \\
\text { difference vs. placebo } \\
\text { in change from base- } \\
\text { line (\% points): range, } \\
-44 \% \text { to }-61 \%\end{array}$ \\
\hline \multicolumn{9}{|c|}{ HDL-C raising ability } \\
\hline $\begin{array}{l}\text { HDL-C: } \\
\text { Moderate }\end{array}$ & 2 RCTs, $N=499$ & Low & Direct & Consistent & Imprecise & Undetected & None & $\begin{array}{l}\text { Greater increase for } \\
\text { evolocumab: absolute } \\
\text { difference vs. placebo } \\
\text { in change from base- } \\
\text { line (\% points): range, } \\
6.8 \% \text { to } 9.2 \%\end{array}$ \\
\hline \multicolumn{9}{|c|}{ Overall adverse events } \\
\hline $\begin{array}{l}\text { Overall AE: } \\
\text { Moderate }\end{array}$ & 2 RCTs, $N=499$ & Low & Direct & Consistent & Imprecise & Undetected & None & $\begin{array}{l}\text { No difference; } 58 \% \text { vs. } \\
52 \% \text {; EPC-pooled RR } \\
1.12(95 \% \text { CI, } 0.94 \text { to } \\
1.33)\end{array}$ \\
\hline \multicolumn{9}{|c|}{ Withdrawals due to adverse events } \\
\hline $\begin{array}{l}\text { AE withdrawal: } \\
\text { Moderate }\end{array}$ & 2 RCTs, $\mathrm{N}=499$ & Low & Direct & Consistent & Imprecise & Undetected & None & $\begin{array}{l}\text { No difference; } 0.6 \% \\
\text { vs. } 0.6 \% \text {; pooled RR } \\
\text { not possible because } \\
\text { of no events in } \\
\text { RUTHERFORD-2 }\end{array}$ \\
\hline \multicolumn{9}{|c|}{ Serious adverse events } \\
\hline $\begin{array}{l}\text { Serious AE: } \\
\text { Moderate }\end{array}$ & 2 RCTs, $N=499$ & Low & Direct & Consistent & Imprecise & Undetected & None & $\begin{array}{l}\text { No difference; 3\% vs. } \\
\text { 3\%; EPC-pooled } \\
\text { RR } 0.81 \text { ( } 95 \% \\
\text { CI, } 0.28 \text { to } 2.33)\end{array}$ \\
\hline \multicolumn{9}{|c|}{ Specific adverse events: neurocognitive events } \\
\hline $\begin{array}{l}\text { Neurocognitive } \\
\text { dysfunction: } \\
\text { Moderate }\end{array}$ & 2 RCTs, $N=499$ & Low & Direct & Consistent & Imprecise & Undetected & None & No events \\
\hline \multicolumn{9}{|c|}{ Specific adverse events: injection site } \\
\hline $\begin{array}{l}\text { Injection site: } \\
\text { Moderate }\end{array}$ & 2 RCTs, $\mathrm{N}=499$ & Low & Direct & Consistent & Imprecise & Undetected & None & $\begin{array}{l}6 \% \text { vs. } 3 \% ; \text { EPC- } \\
\text { pooled RR } 0.76(95 \% \\
\text { CI, } 0.76 \text { to } 5.21)\end{array}$ \\
\hline
\end{tabular}




\section{APPENDIX B Strength of Evidence (continued)}

\begin{tabular}{|c|c|c|c|c|c|c|c|c|}
\hline $\begin{array}{l}\text { Strength of } \\
\text { Evidence Grade }\end{array}$ & $\begin{array}{l}\text { Study Design; } \\
\text { No. Studies (N) }\end{array}$ & $\begin{array}{c}\text { Study } \\
\text { Limitations }\end{array}$ & Directness & Consistency & Precision & $\begin{array}{l}\text { Reporting } \\
\text { Bias }\end{array}$ & Other Issues & Finding \\
\hline \multicolumn{9}{|c|}{ Key Question 2. Homozygous Familiar Hypercholesterolemia } \\
\hline \multicolumn{9}{|c|}{ Evolocumab $420 \mathrm{mg}$ Q4 weeks $\times 12$ weeks in patients taking a statin with or without ezetimibe vs. placebo } \\
\hline \multicolumn{9}{|c|}{ LDL-C lowering ability } \\
\hline $\begin{array}{l}\text { Evolocumab } \\
\text { vs. Placebo: } \\
\text { Low }\end{array}$ & $\begin{array}{l}\text { RCT } \\
1(50)\end{array}$ & Low & Direct & Unknown & Imprecise & Not detected & None & $\begin{array}{l}\text { Evolocumab signifi- } \\
\text { cantly reduced ultra- } \\
\text { centrifugation LDL-C } \\
\text { at } 12 \text { weeks by } 32.1 \% \\
(95 \% \text { CI, } 45.1 \text { to }-19.2 \text { ) } \\
\text { compared to placebo }\end{array}$ \\
\hline \multicolumn{9}{|c|}{ HDL-C raising ability } \\
\hline $\begin{array}{l}\text { Evolocumab } \\
\text { vs. Placebo: } \\
\text { Low }\end{array}$ & $\begin{array}{l}\text { RCT } \\
1(50)\end{array}$ & Low & Direct & Unknown & Imprecise & Not detected & None & $\begin{array}{l}\text { Evolocumab reduced } \\
\text { HDL-C by } 0.1 \%(95 \% \\
\text { CI, }-9.4 \% \text { to } 9.2 \% \text { ) at } \\
\text { week } 12 \text { compared to } \\
\text { placebo (NS) }\end{array}$ \\
\hline \multicolumn{9}{|c|}{ Overall adverse events } \\
\hline $\begin{array}{l}\text { Evolocumab } \\
\text { vs. Placebo: } \\
\text { Low }\end{array}$ & $\begin{array}{l}\text { RCT } \\
1(50)\end{array}$ & Low & Direct & Unknown & Imprecise & Not detected & None & $\begin{array}{l}\text { Any treatment emer- } \\
\text { gent adverse events: } \\
\text { Evolocumab vs. } \\
\text { Placebo: } 36 \%(12 / 33) \\
\text { vs. } 63 \%(10 / 16)\end{array}$ \\
\hline \multicolumn{9}{|c|}{ Withdrawals due to adverse events } \\
\hline $\begin{array}{l}\text { Evolocumab } \\
\text { vs. Placebo: } \\
\text { Low }\end{array}$ & $\begin{array}{l}\text { RCT } \\
l(50)\end{array}$ & Low & Direct & Unknown & Imprecise & Not detected & None & $\begin{array}{l}\text { No difference in treat- } \\
\text { ment emergent adverse } \\
\text { events leading to dis- } \\
\text { continuation of study } \\
\text { drug: Evolocumab vs. } \\
\text { Placebo: } 0 \%(0 / 33) \text { vs. } \\
0 \%(0 / 16)\end{array}$ \\
\hline \multicolumn{9}{|c|}{ Serious adverse events } \\
\hline $\begin{array}{l}\text { Evolocumab } \\
\text { vs. Placebo: } \\
\text { Low }\end{array}$ & $\begin{array}{l}\text { RCT } \\
1(50)\end{array}$ & Low & Direct & Unknown & Imprecise & Not detected & None & $\begin{array}{l}\text { No difference in seri- } \\
\text { ous treatment emer- } \\
\text { gent adverse events: } \\
\text { Evolocumab vs. } \\
\text { Placebo: } 0 \%(0 / 33) \text { vs. } \\
0 \%(0 / 16)\end{array}$ \\
\hline \multicolumn{9}{|c|}{ Specific adverse events: neurocognitive events ${ }^{a}$} \\
\hline $\begin{array}{l}\text { Evolocumab } \\
\text { vs. Placebo: } \\
\text { Low }\end{array}$ & $\begin{array}{l}\text { RCT } \\
1(50)\end{array}$ & Low & Direct & Unknown & Imprecise & Not detected & None & $\begin{array}{l}\text { No difference between } \\
\text { groups in neuro- } \\
\text { cognitive events: } \\
\text { Evolocumab vs. } \\
\text { Placebo: } 0 \%(0 / 33) \text { vs. } \\
0 \%(0 / 16)\end{array}$ \\
\hline \multicolumn{9}{|c|}{ Specific adverse events: potential injection-site reactions ${ }^{b}$} \\
\hline $\begin{array}{l}\text { Evolocumab } \\
\text { vs. Placebo: } \\
\text { Low }\end{array}$ & $\begin{array}{l}\text { RCT } \\
1(50)\end{array}$ & Low & Direct & Unknown & Imprecise & Not detected & None & $\begin{array}{l}\text { Potential injection-site } \\
\text { reactions: Evolocumab } \\
\text { vs. Placebo: } 0 \%(0 / 33) \\
\text { vs. } 6 \%(1 / 16)\end{array}$ \\
\hline \multicolumn{9}{|c|}{ Specific adverse events: gastroenteritis } \\
\hline $\begin{array}{l}\text { Evolocumab } \\
\text { vs. Placebo: } \\
\text { Low }\end{array}$ & $\begin{array}{l}\text { RCT } \\
1(50)\end{array}$ & Low & Direct & Unknown & Imprecise & Not detected & None & $\begin{array}{l}\text { Gastroenteritis: } \\
\text { Evolocumab vs. } \\
\text { Placebo: 6\% (2/33) vs. } \\
0 \%(0 / 16)\end{array}$ \\
\hline
\end{tabular}




\section{APPENDIX B Strength of Evidence (continued)}

\begin{tabular}{|c|c|c|c|c|c|c|c|c|}
\hline $\begin{array}{l}\text { Strength of } \\
\text { Evidence Grade }\end{array}$ & $\begin{array}{l}\text { Study Design; } \\
\text { No. Studies (N) }\end{array}$ & $\begin{array}{c}\text { Study } \\
\text { Limitations }\end{array}$ & Directness & Consistency & Precision & $\begin{array}{c}\text { Reporting } \\
\text { Bias }\end{array}$ & Other Issues & Finding \\
\hline \multicolumn{9}{|c|}{ Key Question 3. Not at Target } \\
\hline \multicolumn{9}{|c|}{ Alirocumab 150 mg Q2 weeks $\times 8$-12 weeks vs. placebo } \\
\hline \multicolumn{9}{|c|}{ LDL-C lowering ability } \\
\hline \multicolumn{9}{|c|}{$\%$ at target $(<70 \mathrm{mg} / \mathrm{dl})$} \\
\hline $\begin{array}{l}\text { Alirocumab+ } \\
\text { low-dose } \\
\text { statin vs. } \\
\text { Placebo+ } \\
\text { high-dose } \\
\text { statin } \\
\text { Low }\end{array}$ & $\begin{array}{l}\text { RCT } \\
1(61)\end{array}$ & Medium & Direct & Unknown & Imprecise & Not detected & None & $100 \%$ vs. $52 \%$ \\
\hline $\begin{array}{l}\text { Alirocumab } \\
\text { vs. Placebo + } \\
\text { low-moderate } \\
\text { dose statin } \\
\text { Low }\end{array}$ & $\begin{array}{l}\text { RCT } \\
1(31)\end{array}$ & Medium & Direct & Unknown & Imprecise & Not detected & None & $100 \%$ vs. $16.1 \%$ \\
\hline $\begin{array}{l}\text { Alirocumab } \\
\text { vs. Placebo+ } \\
\text { high-dose } \\
\text { statin } \\
\text { Low }\end{array}$ & $\begin{array}{l}\text { RCT } \\
1(62)\end{array}$ & Medium & Direct & Unknown & Imprecise & Not detected & None & $100 \%$ vs. $52 \%$ \\
\hline \multicolumn{9}{|c|}{ \% change in LDL } \\
\hline $\begin{array}{l}\text { Alirocumab } \\
+ \text { low-dose } \\
\text { statin vs. } \\
\text { Placebo+ } \\
\text { high-dose } \\
\text { statin } \times 8 \text { wks } \\
\text { Low }\end{array}$ & $\begin{array}{l}\text { RCT } \\
1(61)\end{array}$ & Medium & Direct & Unknown & Imprecise & Not detected & None & $\begin{array}{l}\text { Difference in LDL-C } \\
\text { lowering: } 48.9 \%, \\
P<0.001\end{array}$ \\
\hline $\begin{array}{l}\text { Alirocumab } \\
\text { vs. Placebo }+ \\
\text { moderate } \\
\text { dose statin } \times \\
12 \text { wks } \\
\text { Low }\end{array}$ & $\begin{array}{l}\text { RCT } \\
1(31)\end{array}$ & Medium & Direct & Unknown & Imprecise & Not detected & None & $\begin{array}{l}\text { Difference in LDL-C } \\
\text { lowering: } 67.3 \% \\
P<0.001\end{array}$ \\
\hline \multicolumn{9}{|l|}{$\%$ change in LDL } \\
\hline $\begin{array}{l}\text { Alirocumab } \\
\text { vs. Placebo }+ \\
\text { high-dose } \\
\text { statin } \times 8 \text { wks } \\
\text { Low }\end{array}$ & $\begin{array}{l}\text { RCT } \\
1(62)\end{array}$ & Medium & Direct & Unknown & Imprecise & Not detected & None & $\begin{array}{l}\text { Difference in LDL-C } \\
\text { lowering: } 55.9 \%, \\
P<0.001\end{array}$ \\
\hline \multicolumn{9}{|c|}{$\%$ change in HDL } \\
\hline $\begin{array}{l}\text { Alirocumab } \\
+ \text { low-dose } \\
\text { statin vs. } \\
\text { Placebo }+ \\
\text { high-dose } \\
\text { statin } \times 8 \text { wks } \\
\text { Low }\end{array}$ & $\begin{array}{l}\text { RCT } \\
1(61)\end{array}$ & Medium & Direct & Unknown & Imprecise & Not detected & None & $\begin{array}{l}\text { Difference in HDL-C } \\
\text { lowering: } 6 \mathrm{mg} / \mathrm{dl} ; \\
P=0.06\end{array}$ \\
\hline $\begin{array}{l}\text { Alirocumab } \\
\text { vs. Placebo } \\
+ \text { moderate } \\
\text { dose statin } \\
\times 12 \text { wks } \\
\text { Low }\end{array}$ & $\begin{array}{l}\text { RCT } \\
1(31)\end{array}$ & Medium & Direct & Unknown & Imprecise & Not detected & None & $\begin{array}{l}\text { Difference in HDL-C } \\
\text { lowering: } 6.5 \mathrm{mg} / \mathrm{dl} \text {; } \\
P=0.057\end{array}$ \\
\hline $\begin{array}{l}\text { Alirocumab } \\
\text { vs. Placebo }+ \\
\text { high-dose } \\
\text { statin } \times 8 \text { wks } \\
\text { Low }\end{array}$ & $\begin{array}{l}\text { RCT } \\
1(62)\end{array}$ & Medium & Direct & Unknown & Imprecise & Not detected & None & $\begin{array}{l}\text { Difference in HDL-C } \\
\text { lowering: } 9.4 \mathrm{mg} / \mathrm{dL} \text {; } \\
P=0.05\end{array}$ \\
\hline
\end{tabular}




\section{APPENDIX B Strength of Evidence (continued)}

\begin{tabular}{|c|c|c|c|c|c|c|c|c|}
\hline $\begin{array}{l}\text { Strength of } \\
\text { Evidence Grade }\end{array}$ & $\begin{array}{l}\text { Study Design; } \\
\text { No. Studies (N) }\end{array}$ & $\begin{array}{c}\text { Study } \\
\text { Limitations }\end{array}$ & Directness & Consistency & Precision & $\begin{array}{l}\text { Reporting } \\
\text { Bias }\end{array}$ & Other Issues & Finding \\
\hline \multicolumn{9}{|c|}{ Overall adverse events } \\
\hline $\begin{array}{l}\text { Alirocumab + } \\
\text { low-dose statin } \\
\text { vs. Placebo }+ \\
\text { high-dose } \\
\text { statin } \\
\text { Insufficient }\end{array}$ & $\begin{array}{l}\text { RCT } \\
1(61)\end{array}$ & Medium & Direct & Unknown & Imprecise & Not detected & None & $61 \%$ vs. $45 \%$ \\
\hline $\begin{array}{l}\text { Alirocumab vs. } \\
\text { Placebo + low/ } \\
\text { moderate-dose } \\
\text { statin } \\
\text { Insufficient }\end{array}$ & $\begin{array}{l}\text { RCT } \\
l(31)\end{array}$ & Medium & Direct & Unknown & Imprecise & Not detected & None & $61.3 \%$ vs. $45.2 \%$ \\
\hline $\begin{array}{l}\text { Alirocumab vs. } \\
\text { Placebo }+ \\
\text { high-dose } \\
\text { statin } \\
\text { Insufficient }\end{array}$ & $\begin{array}{l}\text { RCT } \\
1(62)\end{array}$ & Medium & Direct & Unknown & Imprecise & Not detected & None & $61 \%$ vs. $60 \%$ \\
\hline \multicolumn{9}{|c|}{ Withdrawals due to adverse events } \\
\hline $\begin{array}{l}\text { Alirocumab }+ \\
\text { low-dose statin } \\
\text { vs. Placebo }+ \\
\text { high-dose statin } \\
\text { Insufficient }\end{array}$ & $\begin{array}{l}\mathrm{RCT} \\
1(61)\end{array}$ & Medium & Direct & Unknown & Imprecise & Not detected & None & $0 \%$ vs. $13 \%$ \\
\hline $\begin{array}{l}\text { Alirocumab vs. } \\
\text { Placebo + low/ } \\
\text { moderate-dose } \\
\text { statin } \\
\text { Insufficient }\end{array}$ & $\begin{array}{l}\text { RCT } \\
1(31)\end{array}$ & Medium & Direct & Unknown & Imprecise & Not detected & None & $3.2 \%$ vs. $0 \%$ \\
\hline $\begin{array}{l}\text { Alirocumab vs. } \\
\text { Placebo + high- } \\
\text { dose statin } \\
\text { Insufficient }\end{array}$ & $\begin{array}{l}\text { RCT } \\
l(62)\end{array}$ & Medium & Direct & Unknown & Imprecise & Not detected & None & $3 \%$ vs. $13 \%$ \\
\hline \multicolumn{9}{|c|}{ Serious adverse events } \\
\hline $\begin{array}{l}\text { Alirocumab }+ \\
\text { low-dose statin } \\
\text { vs. Placebo }+ \\
\text { high-dose statin }\end{array}$ & $\begin{array}{l}\text { RCT } \\
1(61)\end{array}$ & Medium & Direct & Unknown & Imprecise & Not detected & None & 0 vs. 0 \\
\hline $\begin{array}{l}\text { Alirocumab vs. } \\
\text { Placebo + low/ } \\
\text { moderate-dose } \\
\text { statin }\end{array}$ & $\begin{array}{l}\text { RCT } \\
1(31)\end{array}$ & Medium & Direct & Unknown & Imprecise & Not detected & None & $0 \%$ vs. $3.2 \%$ \\
\hline $\begin{array}{l}\text { Alirocumab vs. } \\
\text { Placebo + high- } \\
\text { dose statin } \\
\text { Insufficient }\end{array}$ & $\begin{array}{l}\mathrm{RCT} \\
1(62)\end{array}$ & Medium & Direct & Unknown & Imprecise & Not detected & None & $0 \%$ vs. $3 \%$ \\
\hline \multicolumn{9}{|c|}{ Specific adverse events: potential injection-site reactions ${ }^{b}$} \\
\hline $\begin{array}{l}\text { Alirocumab + } \\
\text { low-dose statin } \\
\text { vs. Placebo }+ \\
\text { high-dose statin }\end{array}$ & $\begin{array}{l}\mathrm{RCT} \\
1(61)\end{array}$ & Medium & Direct & Unknown & Imprecise & Not detected & None & $0 \%$ vs. $6.5 \%$ \\
\hline $\begin{array}{l}\text { Alirocumab vs. } \\
\text { Placebo + low/ } \\
\text { moderate-dose } \\
\text { statin } \\
\text { Insufficient }\end{array}$ & $\begin{array}{l}\text { RCT } \\
1(31)\end{array}$ & Medium & Direct & Unknown & Imprecise & Not detected & None & 3.2 to $32 \%$ vs. $0 \%$ \\
\hline $\begin{array}{l}\text { Alirocumab vs. } \\
\text { Placebo + high- } \\
\text { dose statin } \\
\text { Insufficient }\end{array}$ & $\begin{array}{l}\text { RCT } \\
1(62)\end{array}$ & Medium & Direct & Unknown & Imprecise & Not detected & None & $3.3 \%$ vs. $6.5 \%$ \\
\hline
\end{tabular}




\section{APPENDIX B Strength of Evidence (continued)}

\begin{tabular}{|c|c|c|c|c|c|c|c|c|}
\hline $\begin{array}{l}\text { Strength of } \\
\text { Evidence Grade }\end{array}$ & $\begin{array}{l}\text { Study Design; } \\
\text { No. Studies (N) }\end{array}$ & $\begin{array}{c}\text { Study } \\
\text { Limitations }\end{array}$ & Directness & Consistency & Precision & $\begin{array}{l}\text { Reporting } \\
\text { Bias }\end{array}$ & Other Issues & Finding \\
\hline \multicolumn{9}{|c|}{ Alirocumab $75 \mathrm{mg}$ to $150 \mathrm{mg}$ Q 2 weeks vs. placebo at 24 weeks in high-risk patients } \\
\hline \multicolumn{9}{|c|}{ LDL-C lowering ability } \\
\hline \multicolumn{9}{|c|}{$\%$ at target $(<70 \mathrm{mg} / \mathrm{dl})$} \\
\hline $\begin{array}{l}\text { Alirocumab+ } \\
\text { max-dose } \\
\text { statin vs. } \\
\text { Placebo+ } \\
\text { max-dose } \\
\text { statin } \\
\text { High }\end{array}$ & $\begin{array}{l}\text { RCT } \\
2(2,656)\end{array}$ & Low & Direct & Consistent & Precise & Not detected & None & $\begin{array}{l}\text { Pooled RR } 9.65 \text { (95\% } \\
\text { CI, } 7.7 \text { to } 12.0) \\
\text { ( } 75-79 \% \text { vs. } 8-9 \%)\end{array}$ \\
\hline $\begin{array}{l}\text { Alirocumab }+ \\
\text { max-dose } \\
\text { statin vs. } \\
\text { ezetimibe } \\
10 \text { mg }+ \\
\text { max-dose } \\
\text { statin } \\
\text { Moderate }\end{array}$ & $\begin{array}{l}\text { RCT } \\
1(720)\end{array}$ & Low & Direct & Unknown & Precise & Not detected & None & $\begin{array}{l}77 \% \text { vs. } 45.6 \% \\
\text { RR } 1.70(95 \% \mathrm{CI} \\
1.46 \text { to } 1.95)\end{array}$ \\
\hline \multicolumn{9}{|l|}{$\%$ change in $L D L$} \\
\hline $\begin{array}{l}\text { Alirocumab + } \\
\text { max-dose } \\
\text { statin vs. } \\
\text { Placebo + } \\
\text { max-dose } \\
\text { statin } \\
\text { High }\end{array}$ & $\begin{array}{l}\text { RCT } \\
2(2,656)\end{array}$ & Low & Direct & Consistent & Precise & Not detected & None & $\begin{array}{l}\text { Differenc }=-45.9 \%, \\
P<0.001 \text { (primarily } \\
75 \mathrm{mg} \mathrm{Q2} \mathrm{wks)} \\
-61.9 \%, P<0.001 \\
(150 \mathrm{mg} \mathrm{Q} 2 \text { wks) }\end{array}$ \\
\hline $\begin{array}{l}\text { Alirocumab } \\
+ \text { max-dose } \\
\text { statin vs. } \\
\text { ezetimibe } 10 \\
\text { mg + max- } \\
\text { dose statin } \\
\text { Moderate }\end{array}$ & $\begin{array}{l}\mathrm{RCT} \\
1(720)\end{array}$ & Low & Direct & Unknown & Precise & Not detected & None & $\begin{array}{l}\text { Difference }=-29.8 \% \\
P<0.001\end{array}$ \\
\hline \multicolumn{9}{|l|}{$\%$ change in HDL } \\
\hline $\begin{array}{l}\text { Alirocumab } \\
+ \text { max-dose } \\
\text { statin vs. } \\
\text { Placebo + } \\
\text { max-dose } \\
\text { statin } \\
\text { Moderate } \\
\end{array}$ & $\begin{array}{l}\text { RCT } \\
2(2,656)\end{array}$ & Low & Direct & Consistent & Imprecise & Not detected & None & $\begin{array}{l}7.3,95 \% \mathrm{Cl}, 3.6 \text { to } \\
11.0 ; P<0.001 \\
\text { (primarily } 75 \mathrm{mg} \mathrm{Q2} \\
\text { wks) } 4.6(0.7) ; 3.3 \text { to } \\
5.9, P<0.001(150 \mathrm{mg} \\
Q 2 \text { wks) }\end{array}$ \\
\hline $\begin{array}{l}\text { Alirocumab+ } \\
\text { max-dose } \\
\text { statin vs. } \\
\text { ezetimibe } \\
10 \text { mg + } \\
\text { max-dose } \\
\text { statin } \\
\text { Low }\end{array}$ & $\begin{array}{l}\text { RCT } \\
1(720)\end{array}$ & Low & Direct & Unknown & Imprecise & Not detected & None & $\begin{array}{l}\text { Difference }= \\
8.1 \%(1.3), P<0.001\end{array}$ \\
\hline \multicolumn{9}{|c|}{ Overall adverse events } \\
\hline $\begin{array}{l}\text { Alirocumab }+ \\
\text { max-dose statin } \\
\text { vs. Placebo }+ \\
\text { max-dose statin } \\
\text { High }\end{array}$ & $\begin{array}{l}\text { RCT } \\
2(2,656)\end{array}$ & Low & Direct & Consistent & Precise & Not detected & None & $\begin{array}{l}81.0 \% \text { vs. } 82.5 \% \\
75.8 \% \text { vs. } 75.7 \%\end{array}$ \\
\hline $\begin{array}{l}\text { Alirocumab }+ \\
\text { max-dose } \\
\text { statin vs. ezeti- } \\
\text { mibe } 10 \mathrm{mg}+ \\
\text { max-dose } \\
\text { statin } \\
\text { Moderate }\end{array}$ & $\begin{array}{l}\mathrm{RCT} \\
1(720)\end{array}$ & Low & Direct & Unknown & Precise & Not detected & None & $71.2 \%$ vs. $67.2 \%$ \\
\hline
\end{tabular}




\section{APPENDIX B Strength of Evidence (continued)}

\begin{tabular}{|c|c|c|c|c|c|c|c|c|}
\hline $\begin{array}{l}\text { Strength of } \\
\text { Evidence Grade }\end{array}$ & $\begin{array}{l}\text { Study Design; } \\
\text { No. Studies (N) }\end{array}$ & $\begin{array}{c}\text { Study } \\
\text { Limitations }\end{array}$ & Directness & Consistency & Precision & $\begin{array}{l}\text { Reporting } \\
\text { Bias }\end{array}$ & Other Issues & Finding \\
\hline \multicolumn{9}{|c|}{ Withdrawals due to adverse events } \\
\hline $\begin{array}{l}\text { Alirocumab }+ \\
\text { max-dose } \\
\text { statin vs. } \\
\text { Placebo }+ \\
\text { max-dose statin } \\
\text { Moderate }\end{array}$ & $\begin{array}{l}\text { RCT } \\
2(2,656)\end{array}$ & Low & Direct & Consistent & Imprecise & Not detected & None & $\begin{array}{l}7.2 \% \text { vs. } 5.8 \% \\
6.3 \% \text { vs. } 7.5 \%\end{array}$ \\
\hline $\begin{array}{l}\text { Alirocumab+ } \\
\text { max-dose } \\
\text { statin vs. ezeti- } \\
\text { mibe } 10 \mathrm{mg}+ \\
\text { max-dose } \\
\text { statin } \\
\text { Low }\end{array}$ & $\begin{array}{l}\text { RCT } \\
1(720)\end{array}$ & Low & Direct & Unknown & Imprecise & Not detected & None & $7.5 \%$ vs. $5.4 \%$ \\
\hline \multicolumn{9}{|c|}{ Serious adverse events } \\
\hline $\begin{array}{l}\text { Alirocumab }+ \\
\text { max-dose } \\
\text { statin vs. } \\
\text { Placebo }+ \\
\text { max-dose } \\
\text { statin } \\
\text { High } \\
\end{array}$ & $\begin{array}{l}\text { RCT } \\
2(2,656)\end{array}$ & Low & Direct & Consistent & Precise & Not detected & None & $\begin{array}{l}18.7 \% \text { vs. } 19.5 \% \\
12.6 \% \text { vs. } 13.1 \%\end{array}$ \\
\hline $\begin{array}{l}\text { Alirocumab }+ \\
\text { max-dose } \\
\text { statin vs. } \\
\text { ezetimibe } \\
10 \mathrm{mg}+ \\
\text { max-dose } \\
\text { statin } \\
\text { Low }\end{array}$ & $\begin{array}{l}\text { RCT } \\
1(720)\end{array}$ & Low & Direct & Unknown & Imprecise & Not detected & None & $18.8 \%$ vs. $17.8 \%$ \\
\hline \multicolumn{9}{|c|}{ Specific adverse events: potential injection-site reactions ${ }^{b}$} \\
\hline \begin{tabular}{l|} 
Alirocumab + \\
max-dose \\
statin vs. \\
Placebo + \\
max-dose \\
statin \\
Low \\
\end{tabular} & $\begin{array}{l}\text { RCT } \\
2(2,656)\end{array}$ & Low & Direct & Inconsistent & Imprecise & Not detected & None & $\begin{array}{l}\text { Pooled RR } 1.4 \text { ( } 95 \% \\
\text { CI, } 0.98 \text { to } 2.1) \\
\text { Rates } 5.9 \% \text { vs. } 4.2 \% \\
\text { and } 5.3 \% \text { vs. } 2.8 \%\end{array}$ \\
\hline $\begin{array}{l}\text { Alirocumab+ } \\
\text { max-dose } \\
\text { statin vs. } \\
\text { ezetimibe } \\
10 \mathrm{mg}+\mathrm{max}- \\
\text { dose statin } \\
\text { Low }\end{array}$ & $\begin{array}{l}\text { RCT } \\
1(720)\end{array}$ & Low & Direct & Unknown & Imprecise & Not detected & None & $2.5 \%$ vs. $0.8 \%$ \\
\hline \multicolumn{9}{|c|}{ Specific adverse events } \\
\hline \multicolumn{9}{|c|}{ Neurocognitive events } \\
\hline $\begin{array}{l}\text { Alirocumab } \\
+ \text { max-dose } \\
\text { statin vs. } \\
\text { Placebo+ } \\
\text { max-dose } \\
\text { statin } \\
\text { Moderate } \\
\end{array}$ & $\begin{array}{l}\mathrm{RCT} \\
2(2,656)\end{array}$ & Low & Direct & Consistent & Imprecise & Not detected & None & $\begin{array}{l}1.2 \% \text { vs. } 0.5 \% ; P=0.17 \\
0 \text { vs. } 0.9 \%\end{array}$ \\
\hline $\begin{array}{l}\text { Alirocumab } \\
+ \text { max-dose } \\
\text { statin vs. } \\
\text { ezetimibe } \\
10 \mathrm{mg}+ \\
\text { max-dose } \\
\text { statin } \\
\text { Low }\end{array}$ & $\begin{array}{l}\text { RCT } \\
1(720)\end{array}$ & Low & Direct & Unknown & Imprecise & Not detected & None & $0.8 \%$ vs. $1.2 \%$ \\
\hline
\end{tabular}




\section{APPENDIX B Strength of Evidence (continued)}

\begin{tabular}{|c|c|c|c|c|c|c|c|c|}
\hline $\begin{array}{l}\text { Strength of } \\
\text { Evidence Grade }\end{array}$ & $\begin{array}{l}\text { Study Design; } \\
\text { No. Studies (N) }\end{array}$ & $\begin{array}{c}\text { Study } \\
\text { Limitations }\end{array}$ & Directness & Consistency & Precision & $\begin{array}{l}\text { Reporting } \\
\text { Bias }\end{array}$ & Other Issues & Finding \\
\hline \multicolumn{9}{|c|}{ CV events (adjudicated) } \\
\hline $\begin{array}{l}\text { Alirocumab+ } \\
\text { max-dose } \\
\text { statin vs. } \\
\text { Placebo+ } \\
\text { max-dose } \\
\text { statin } \\
\text { Moderate } \\
\end{array}$ & $\begin{array}{l}\text { RCT } \\
2(2,656)\end{array}$ & Low & Direct & Consistent & Imprecise & Not detected & None & $\begin{array}{l}\text { Pooled RR } 0.91 \text { ( } 95 \% \\
\text { CI, } 0.63 \text { to } 1.31)\end{array}$ \\
\hline $\begin{array}{l}\text { Alirocumab+ } \\
\text { max-dose } \\
\text { statin vs. } \\
\text { ezetimibe } \\
10 \mathrm{mg} \\
+ \text { max-dose } \\
\text { statin } \\
\text { Low }\end{array}$ & $\begin{array}{l}\text { RCT } \\
1(720)\end{array}$ & Low & Direct & Unknown & Imprecise & Not detected & None & $\begin{array}{l}\text { RR } 1.29(95 \% \text { CI, } 0.60 \\
\text { to } 2.74)\end{array}$ \\
\hline \multicolumn{9}{|c|}{ Evolocumab $420 \mathrm{mg}$ Q4 weeks $\times 52$ weeks vs. placebo } \\
\hline \multicolumn{9}{|c|}{ LDL-C lowering ability } \\
\hline \multicolumn{9}{|c|}{$\%$ at target $(<70 \mathrm{mg} / \mathrm{dl})$} \\
\hline $\begin{array}{l}\text { Evolocumab } \\
420 \text { mg Q } 4 \\
\text { weeks } \times 48 \\
\text { weeks vs. } \\
\text { Placebo } \\
\text { Moderate }\end{array}$ & $\begin{array}{l}\mathrm{RCT} \\
1(901)\end{array}$ & Low & Direct & Unknown & Precise & Not detected & None & $\begin{array}{l}82.3 \% \text { evolocumab } \\
\text { vs. } 6.4 \% \text { placebo; } \\
P<0.001\end{array}$ \\
\hline \multicolumn{9}{|c|}{$\%$ change in LDL at 52 weeks } \\
\hline $\begin{array}{l}\text { Evolocumab } \\
420 \text { mg Q } 4 \\
\text { weeks × } 48 \\
\text { weeks vs. } \\
\text { Placebo: } \\
\text { Moderate }\end{array}$ & $\begin{array}{l}\text { RCT } \\
1(901)\end{array}$ & Low & Direct & Unknown & Precise & Not detected & None & $\begin{array}{l}\text { Difference in ultracen- } \\
\text { trifugation LDL-C at } \\
52 \text { weeks }-57 \%( \pm 2.1 \\
\text { SD) compared to } \\
\text { placebo }\end{array}$ \\
\hline \multicolumn{9}{|c|}{$\%$ change in HDL at 52 weeks } \\
\hline $\begin{array}{l}\text { Evolocumab } \\
420 \text { mg Q } 4 \\
\text { weeks × } 48 \\
\text { weeks vs. } \\
\text { Placebo: } \\
\text { Low } \\
\end{array}$ & $\begin{array}{l}\text { RCT } \\
1(901)\end{array}$ & Low & Direct & Unknown & Imprecise & Not detected & None & $\begin{array}{l}\text { Difference vs. pla- } \\
\text { cebo in \% change } \\
\text { from baseline: } 5.4 \% \text {; } \\
P<0.001\end{array}$ \\
\hline \multicolumn{9}{|c|}{ Overall adverse events } \\
\hline $\begin{array}{l}\text { Evolocumab vs. } \\
\text { Placebo: } \\
\text { Moderate }\end{array}$ & $\begin{array}{l}\mathrm{RCT} \\
1(901)\end{array}$ & Low & Direct & Unknown & Precise & Not detected & None & $\begin{array}{l}\text { Evolocumab vs. } \\
\text { Placebo: } 75 \% \text { vs. } 74 \%\end{array}$ \\
\hline \multicolumn{9}{|c|}{ Withdrawals due to adverse events } \\
\hline $\begin{array}{l}\text { Evolocumab vs. } \\
\text { Placebo: } \\
\text { Low }\end{array}$ & $\begin{array}{l}\mathrm{RCT} \\
1(901)\end{array}$ & Low & Direct & Unknown & Imprecise & Not detected & None & $\begin{array}{l}\text { Evolocumab vs. } \\
\text { Placebo: } 2 \%(13 / 599) \\
\text { vs. 1\% (3/302) }\end{array}$ \\
\hline \multicolumn{9}{|c|}{ Serious adverse events } \\
\hline $\begin{array}{l}\text { Evolocumab vs. } \\
\text { Placebo: } \\
\text { Low }\end{array}$ & $\begin{array}{l}\text { RCT } \\
1(901)\end{array}$ & Low & Direct & Unknown & Imprecise & Not detected & None & $\begin{array}{l}\text { Evolocumab vs. } \\
\text { Placebo: } 6 \% \text { vs. } 4 \%\end{array}$ \\
\hline \multicolumn{9}{|c|}{ Specific adverse events: potential injection-site reactions ${ }^{b}$} \\
\hline $\begin{array}{l}\text { Evolocumab vs. } \\
\text { Placebo: } \\
\text { Low }\end{array}$ & $\begin{array}{l}\text { RCT } \\
1(901)\end{array}$ & Low & Direct & Unknown & Imprecise & Not detected & None & $\begin{array}{l}\text { Evolocumab vs. } \\
\text { Placebo: } 5.7 \%(34 / 599) \\
\text { vs. } 5 \%(15 / 302)\end{array}$ \\
\hline
\end{tabular}




\section{APPENDIX B Strength of Evidence (continued)}

\begin{tabular}{|c|c|c|c|c|c|c|c|c|}
\hline $\begin{array}{l}\text { Strength of } \\
\text { Evidence Grade }\end{array}$ & $\begin{array}{l}\text { Study Design; } \\
\text { No. Studies (N) }\end{array}$ & $\begin{array}{c}\text { Study } \\
\text { Limitations }\end{array}$ & Directness & Consistency & Precision & $\begin{array}{l}\text { Reporting } \\
\text { Bias }\end{array}$ & Other Issues & Finding \\
\hline \multicolumn{9}{|c|}{ Evolocumab 420 mg Q4 weeks $\times 12$ weeks vs. placebo } \\
\hline \multicolumn{9}{|c|}{ LDL-C lowering ability } \\
\hline \multicolumn{9}{|c|}{$\%$ at target $(<70 \mathrm{mg} / \mathrm{dl})$} \\
\hline $\begin{array}{l}\text { Evolocumab } \\
420 \mathrm{mg} \mathrm{Q4} \\
\text { weeks × } 12 \\
\text { weeks vs. } \\
\text { Placebo } \\
\text { High }\end{array}$ & $\begin{array}{l}\text { RCT } \\
2(640 \text { at } 420 \mathrm{mg}, \\
356 \text { placebo })\end{array}$ & Low & Direct & Consistent & Precise & Not detected & None & $\begin{array}{l}72 \% \text { to } 94 \% \text { for evo- } \\
\text { locumab vs. } 0 \% \text { to } 9 \% \\
\text { for placebo; } P<0.001\end{array}$ \\
\hline \multicolumn{9}{|c|}{$\%$ change in LDL at 12 weeks } \\
\hline $\begin{array}{l}\text { Evolocumab } \\
420 \text { mg Q } 4 \\
\text { weeks × } 12 \\
\text { weeks vs. } \\
\text { Placebo: } \\
\text { High }\end{array}$ & $\begin{array}{l}\text { RCT } \\
2(640 \text { at } 420 \mathrm{mg}, \\
356 \text { placebo })\end{array}$ & Low & Direct & Consistent & Precise & Not detected & None & $\begin{array}{l}\text { Difference in ultra- } \\
\text { centrifugation LDL-C } \\
-53 \% \text { ( } 95 \% \text { CI, } 56.0 \text { to } \\
44.6) \text { to }-70.5 \%(95 \% \\
\text { CI, }-79.8 \text { to }-61.2) \\
\text { compared to placebo. }\end{array}$ \\
\hline \multicolumn{9}{|c|}{$\%$ change in HDL at 12 weeks } \\
\hline $\begin{array}{l}\text { Evolocumab } \\
420 \mathrm{mg} \mathrm{Q4} \\
\text { weeks × } 12 \\
\text { weeks vs. } \\
\text { Placebo: } \\
\text { Moderate }\end{array}$ & $\begin{array}{l}\text { RCT } \\
2 \text { (640 at } 420 \mathrm{mg}, \\
356 \text { placebo) }\end{array}$ & Low & Direct & Consistent & Imprecise & Not detected & None & $\begin{array}{l}\text { Difference from } \\
\text { placebo in \% change } \\
\text { from baseline: rang- } \\
\text { ing from } 4.5 \% \text { ( } 95 \% \\
\text { CI, } 0.4 \text { to } 8.7 \text { ) to } 9.1 \% \\
(95 \% \text { CI } 4.4 \text { to } 13.7)\end{array}$ \\
\hline \multicolumn{9}{|c|}{ Overall adverse events } \\
\hline $\begin{array}{l}\text { Evolocumab vs. } \\
\text { Placebo: } \\
\text { High }\end{array}$ & $\begin{array}{l}\text { RCT } \\
2(640 \text { at } 420 \mathrm{mg}, \\
356 \text { placebo })\end{array}$ & Low & Direct & Consistent & Precise & Not detected & None & $\begin{array}{l}\text { Ranged from } 31 \% \text { to } \\
60 \% \text { with evolocumab } \\
420 \text { mg every } 4 \text { weeks } \\
\text { and from } 24 \% \text { to } 49 \% \\
\text { in the placebo group }\end{array}$ \\
\hline \multicolumn{9}{|c|}{ Withdrawals due to adverse events } \\
\hline $\begin{array}{l}\text { Evolocumab vs. } \\
\text { Placebo: } \\
\text { Moderate }\end{array}$ & $\begin{array}{l}\text { RCT } \\
2(640 \text { at } 420 \mathrm{mg}, \\
356 \text { placebo })\end{array}$ & Low & Direct & Consistent & Imprecise & Not detected & None & $\begin{array}{l}\text { Evolocumab vs. } \\
\text { Placebo: } 1-2 \% \text { vs. } 2-4 \%\end{array}$ \\
\hline \multicolumn{9}{|c|}{ Serious adverse events } \\
\hline $\begin{array}{l}\text { Evolocumab vs. } \\
\text { Placebo: } \\
\text { Moderate }\end{array}$ & $\begin{array}{l}\text { RCT } \\
2(640 \text { at } 420 \mathrm{mg}, \\
356 \text { placebo })\end{array}$ & Low & Direct & Consistent & Imprecise & Not detected & None & $\begin{array}{l}\text { No difference, } \\
\text { Evolocumab vs. } \\
\text { Placebo: } 0.9-2.7 \% \text { vs. } \\
1.8-3.6 \%\end{array}$ \\
\hline \multicolumn{9}{|c|}{ Specific adverse events: potential injection-site reactions ${ }^{b}$} \\
\hline $\begin{array}{l}\text { Evolocumab } \\
\text { vs. Placebo: } \\
\text { Moderate }\end{array}$ & $\begin{array}{l}\text { RCT } \\
2(640 \text { at } 420 \mathrm{mg} \\
356 \text { placebo })\end{array}$ & Low & Direct & Consistent & Imprecise & Not detected & None & $\begin{array}{l}\text { No difference, } \\
\text { Evolocumab vs. } \\
\text { Placebo: } 0 \% \text { vs. 1.3\% } \\
\text { in LAPLACE-TIMI-57; } \\
\text { NR by group in } \\
\text { LAPLACE-2 }\end{array}$ \\
\hline \multicolumn{9}{|c|}{$\begin{array}{l}\text { Evolocumab } 420 \mathrm{mg} \text { Q4 weeks } \times 12 \text { weeks vs. placebo, both added to primarily moderate-intensity statins in Japanese patients with high } \\
\text { cardiovascular risk } 11\end{array}$} \\
\hline \multicolumn{9}{|c|}{ LDL-C lowering ability } \\
\hline \multicolumn{9}{|c|}{$\%$ at target $(<70 \mathrm{mg} / \mathrm{dl})$} \\
\hline $\begin{array}{l}\text { Evolocumab } \\
420 \text { mg Q4 } \\
\text { weeks } \\
\times 12 \text { weeks } \\
\text { vs. placebo: } \\
\text { Low }\end{array}$ & $\begin{array}{l}\text { 1 RCT; evolocumab } \\
420 \mathrm{mg} \text { Q4 weeks } \\
\mathrm{N}=53 \text {, placebo every } \\
\text { month } \mathrm{N}=51\end{array}$ & Medium & Direct & Unknown & Imprecise & Not detected & None & $\begin{array}{l}\text { Greater for evo- } \\
\text { locumab: }<100: 96 \% \\
\text { vs. } 1 \% ; P<0.001 \\
<70: 82 \% \text { vs. } 0 \% \\
P<0.001\end{array}$ \\
\hline
\end{tabular}




\section{APPENDIX B Strength of Evidence (continued)}

\begin{tabular}{|c|c|c|c|c|c|c|c|c|}
\hline $\begin{array}{l}\text { Strength of } \\
\text { Evidence Grade }\end{array}$ & $\begin{array}{l}\text { Study Design; } \\
\text { No. Studies (N) }\end{array}$ & $\begin{array}{c}\text { Study } \\
\text { Limitations }\end{array}$ & Directness & Consistency & Precision & $\begin{array}{c}\text { Reporting } \\
\text { Bias }\end{array}$ & Other Issues & Finding \\
\hline \multicolumn{9}{|c|}{$\%$ change in LDL at 12 weeks } \\
\hline $\begin{array}{l}\text { Evolocumab } \\
420 \text { mg Q } 4 \\
\text { weeks × } 12 \\
\text { weeks vs. } \\
\text { placebo: } \\
\text { Low }\end{array}$ & $\begin{array}{l}1 \text { RCT; evolocumab } \\
420 \text { mg Q4 weeks } \\
\mathrm{N}=53 \text {, placebo every } \\
\text { month } \mathrm{N}=51\end{array}$ & Medium & Direct & Unknown & Imprecise & Not detected & None & $\begin{array}{l}\text { Greater for evo- } \\
\text { locumab: Mean \% } \\
\text { change vs. placebo: } \\
-63.9 \% ; P<0.001\end{array}$ \\
\hline \multicolumn{9}{|c|}{$\%$ change in HDL at 12 weeks } \\
\hline $\begin{array}{l}\text { Evolocumab } \\
420 \text { mg Q } \\
4 \text { weeks } \\
\times 12 \text { weeks } \\
\text { vs. placebo: } \\
\text { Insufficient }\end{array}$ & $\begin{array}{l}\text { 1 RCT; evolocumab } \\
420 \text { mg Q4 weeks } \\
\mathrm{N}=53 \text {, placebo every } \\
\text { month } \mathrm{N}=51\end{array}$ & Medium & Direct & Unknown & Imprecise & Not detected & None & $\begin{array}{l}\text { No conclusion: Mean } \\
\% \text { change vs. placebo: } \\
13.2 \% ; P<0.001\end{array}$ \\
\hline \multicolumn{9}{|c|}{ Overall adverse events } \\
\hline $\begin{array}{l}\text { Evolocumab } \\
420 \mathrm{mg} Q 4 \\
\text { weeks × } 12 \\
\text { weeks vs. } \\
\text { placebo: } \\
\text { Insufficient }\end{array}$ & $\begin{array}{l}\text { 1 RCT; evolocumab } \\
420 \text { mg Q } 4 \text { weeks } \\
N=53 \text {, placebo every } \\
\text { month } \mathrm{N}=51\end{array}$ & Medium & Direct & Unknown & Imprecise & Not detected & None & $\begin{array}{l}\text { No conclusion; } \\
58.5 \% \text { vs. } 42.0 \%\end{array}$ \\
\hline \multicolumn{9}{|c|}{ Withdrawals due to adverse events } \\
\hline $\begin{array}{l}\text { Evolocumab } \\
420 \text { mg Q4 } \\
\text { weeks × } 12 \\
\text { weeks vs. } \\
\text { placebo: } \\
\text { Insufficient }\end{array}$ & $\begin{array}{l}\text { 1 RCT; evolocumab } \\
420 \text { mg Q4 weeks } \\
\mathrm{N}=53 \text {, placebo every } \\
\text { month } \mathrm{N}=51\end{array}$ & Medium & Direct & Unknown & Imprecise & Not detected & None & $\begin{array}{l}\text { No conclusion; } \\
3.8 \% \text { vs. } 0\end{array}$ \\
\hline \multicolumn{9}{|c|}{ Serious adverse events } \\
\hline $\begin{array}{l}\text { Evolocumab } \\
420 \text { mg Q4 } \\
\text { weeks × } 12 \\
\text { weeks vs. } \\
\text { placebo: } \\
\text { Insufficient } \\
\end{array}$ & $\begin{array}{l}\text { I RCT; evolocumab } \\
420 \text { mg Q4 weeks } \\
\mathrm{N}=53 \text {, placebo every } \\
\text { month } \mathrm{N}=51\end{array}$ & Medium & Direct & Unknown & Imprecise & Not detected & None & $\begin{array}{l}\text { No conclusion; } \\
3.8 \% \text { vs. } 0\end{array}$ \\
\hline \multicolumn{9}{|c|}{ Specific adverse events: potential injection-site reactions ${ }^{b}$} \\
\hline $\begin{array}{l}\text { Evolocumab } \\
420 \text { mg Q } 4 \\
\text { weeks × } 12 \\
\text { weeks vs. } \\
\text { placebo: } \\
\text { Insufficient }\end{array}$ & $\begin{array}{l}1 \text { RCT; evolocumab } \\
420 \text { mg Q } 4 \text { weeks } \\
\text { N=53, placebo every } \\
\text { month } N=51\end{array}$ & Medium & Direct & Unknown & Imprecise & Not detected & None & $\begin{array}{l}\text { No conclusion; } \\
1.9 \% \text { vs. } 0\end{array}$ \\
\hline \multicolumn{9}{|c|}{ Evolocumab $420 \mathrm{mg} \mathrm{Q} 4$ weeks $\times 12$ weeks vs. ezetimibe $10 \mathrm{mg}$, both added to moderate-high intensity statins } \\
\hline \multicolumn{9}{|c|}{ LDL-C lowering ability } \\
\hline \multicolumn{9}{|c|}{$\%$ at target $(<70 \mathrm{mg} / \mathrm{dl})$} \\
\hline $\begin{array}{l}\text { Evolocumab } \\
420 \mathrm{mg} \mathrm{Q} 4 \\
\text { weeks × } 12 \\
\text { weeks vs. } \\
\text { ezetimibe } \\
10 \mathrm{mg} \text { : } \\
\text { Low }\end{array}$ & $\begin{array}{l}1 \mathrm{RCT} \text {; Atorvastatin } \\
10 \mathrm{mg} \text { group: evo- } \\
\text { locumab } \mathrm{N}=110 \mathrm{vs} \text {. } \\
\text { placebo } \mathrm{N}=55 \\
\text { Atorvastatin } \\
80 \mathrm{mg} \text { group: evo- } \\
\text { locumab } \mathrm{N}=110 \mathrm{vs} \text {. } \\
\text { ezetimibe } \mathrm{N}=54\end{array}$ & Medium & Direct & Unknown & Imprecise & Not detected & None & $\begin{array}{l}\text { Higher for evo- } \\
\text { locumab: Atorvastatin } \\
10 \mathrm{mg}: 85.8 \% \text { vs. } 5.6 \% \text {; } \\
\text { EPC-calculated RR } \\
5.22 \text { (95\% CI, } 3.00 \text { to } \\
9.69) \\
\text { Atorvastatin } 80 \mathrm{mg} \text { : } \\
92.5 \% \text { vs. } 62.3 \% \text {; EPC } \\
\text { calculated RR } 1.47 \\
\text { (95\% CI, } 1.23 \text { to } 1.88)\end{array}$ \\
\hline
\end{tabular}




\section{APPENDIX B Strength of Evidence (continued)}

\begin{tabular}{|c|c|c|c|c|c|c|c|c|}
\hline $\begin{array}{l}\text { Strength of } \\
\text { Evidence Grade }\end{array}$ & $\begin{array}{l}\text { Study Design; } \\
\text { No. Studies (N) }\end{array}$ & $\begin{array}{c}\text { Study } \\
\text { Limitations }\end{array}$ & Directness & Consistency & Precision & $\begin{array}{c}\text { Reporting } \\
\text { Bias }\end{array}$ & Other Issues & Finding \\
\hline \multicolumn{9}{|c|}{ \% change in LDL at 12 weeks } \\
\hline $\begin{array}{l}\text { Evolocumab } \\
420 \text { mg Q } 4 \\
\text { weeks × } 12 \\
\text { weeks vs. } \\
\text { ezetimibe } \\
10 \text { mg: } \\
\text { Low }\end{array}$ & $\begin{array}{l}1 \text { RCT; Atorvastatin } \\
10 \mathrm{mg} \text { group: evo- } \\
\text { locumab } \mathrm{N}=110 \mathrm{vs} \text {. } \\
\text { placebo } \mathrm{N}=55 \\
\text { Atorvastatin } \\
80 \mathrm{mg} \text { group: evo- } \\
\text { locumab } \mathrm{N}=110 \mathrm{vs} \text {. } \\
\text { ezetimibe } \mathrm{N}=54\end{array}$ & Medium & Direct & Unknown & Imprecise & Not detected & None & $\begin{array}{l}\text { Greater for evo- } \\
\text { locumab: \% Change } \\
\text { from baseline ( } 95 \% \\
\mathrm{CI}) \text { : Atorvastatin } 10 \\
\text { mg: }-62.5 \%(95 \% \mathrm{CI} \text {, } \\
-66.1 \text { to }-58.9) \text { vs. } \\
-19.0 \text { (-24.0 to }-13.9) \\
\text { Atorvastatin } 80 \mathrm{mg} \text { : } \\
-65.1 \text { ( } 95 \% \mathrm{CI},-69.8 \\
\text { to }-60.3) \text { vs. }-21.3 \\
(95 \% \mathrm{CI},-28.0 \text { to } \\
-14.5)\end{array}$ \\
\hline \multicolumn{9}{|c|}{$\%$ change in HDL at 12 weeks } \\
\hline $\begin{array}{l}\text { Evolocumab } \\
420 \text { mg Q4 } \\
\text { weeks × } 12 \\
\text { weeks vs. } \\
\text { ezetimibe } \\
10 \text { mg: } \\
\text { Insufficient }\end{array}$ & $\begin{array}{l}1 \text { RCT; Atorvastatin } \\
10 \text { mg group: evo- } \\
\text { locumab } \mathrm{N}=681110 \mathrm{vs} \text {. } \\
\text { placebo } \mathrm{N}=55 \\
\text { Atorvastatin } \\
80 \mathrm{mg} \text { group: evo- } \\
\text { locumab } \mathrm{N}=110 \mathrm{vs} \text {. } \\
\text { ezetimibe } \mathrm{N}=54\end{array}$ & Medium & Direct & Unknown & Imprecise & Not detected & None & $\begin{array}{l}\text { Greater for evo- } \\
\text { locumab: \% Change } \\
\text { from baseline ( } 95 \% \\
\text { CI): Atorvastatin | } \\
10 \mathrm{mg}: 7.7 \text { ( } 95 \% \mathrm{CI}, \\
5.0 \text { to } 10.4 \text { ) vs. }-0.9 \\
\text { (95\% CI, }-4.7 \text { to } 2.9) \\
\text { Atorvastatin } 80 \mathrm{mg} \text { : } \\
7.8 \text { ( } 95 \% \mathrm{CI}, 5.2 \text { to } \\
10.4 \text { ) vs. }-0.6(95 \% \mathrm{CI}, \\
-4.3 \text { to } 3.1 \text { ) }\end{array}$ \\
\hline \multicolumn{9}{|c|}{ Overall adverse events } \\
\hline $\begin{array}{l}\text { Evolocumab } \\
420 \mathrm{mg} \mathrm{Q} 4 \\
\text { weeks × } 12 \\
\text { weeks vs. } \\
\text { ezetimibe } \\
10 \mathrm{mg} \text { : } \\
\text { Low }\end{array}$ & $\begin{array}{l}1 \mathrm{RCT} \text {; Atorvastatin } \\
10 \mathrm{mg} \text { group: evo- } \\
\text { locumab } \mathrm{N}=110 \mathrm{vs} \text {. } \\
\text { placebo } \mathrm{N}=55 \\
\text { Atorvastatin } \\
80 \mathrm{mg} \text { group: evo- } \\
\text { locumab } \mathrm{N}=110 \mathrm{vs} \text {. } \\
\text { ezetimibe } \mathrm{N}=54\end{array}$ & Medium & Direct & Unknown & Imprecise & Not detected & None & $\begin{array}{l}\text { No difference: } \\
\text { Atorvastatin } \\
10 \mathrm{mg}: 30.9 \% \\
\text { vs. } 40.0 \% \\
\text { Atorvastatin } \\
80 \mathrm{mg}: 39.1 \% \\
\text { vs. } 35.2 \%\end{array}$ \\
\hline \multicolumn{9}{|c|}{ Withdrawals due to adverse events } \\
\hline $\begin{array}{l}\text { Evolocumab } \\
420 \mathrm{mg} \mathrm{Q4} \\
\text { weeks × } 12 \\
\text { weeks vs. } \\
\text { ezetimibe } \\
10 \mathrm{mg} \text { : } \\
\text { Insufficient }\end{array}$ & $\begin{array}{l}1 \mathrm{RCT} \text {; Atorvastatin } \\
10 \mathrm{mg} \text { group: evo- } \\
\text { locumab } \mathrm{N}=110 \mathrm{vs} \text {. } \\
\text { placebo } \mathrm{N}=55 \\
\text { Atorvastatin } \\
80 \mathrm{mg} \text { group: evo- } \\
\text { locumab } \mathrm{N}=110 \mathrm{vs} \text {. } \\
\text { ezetimibe } \mathrm{N}=54\end{array}$ & Medium & Direct & Unknown & Imprecise & Not detected & None & $\begin{array}{l}\text { No difference: } \\
\text { Atorvastatin } 10 \mathrm{mg} \text { : } \\
1.8 \% \text { vs. } 0 \\
\text { Atorvastatin } \\
80 \mathrm{mg}: 1.8 \% \\
\text { vs. } 1.9 \%\end{array}$ \\
\hline \multicolumn{9}{|c|}{ Serious adverse events } \\
\hline $\begin{array}{l}\text { Evolocumab } \\
420 \text { mg Q4 } \\
\text { weeks × } 12 \\
\text { weeks vs. ezeti- } \\
\text { mibe } 10 \mathrm{mg}: \\
\text { Insufficient }\end{array}$ & $\begin{array}{l}1 \text { RCT; Atorvastatin } \\
10 \text { mg group: evo- } \\
\text { locumab } \mathrm{N}=110 \mathrm{vs} \text {. } \\
\text { placebo } \mathrm{N}=55 \\
\text { Atorvastatin } \\
80 \mathrm{mg} \text { group: evo- } \\
\text { locumab } \mathrm{N}=110 \mathrm{vs} \text {. } \\
\text { ezetimibe } \mathrm{N}=54\end{array}$ & Medium & Direct & Unknown & Imprecise & Not detected & None & $\begin{array}{l}\text { No difference; } \\
\text { Atorvastatin } \\
10 \text { mg: } 1.8 \% \text { vs. } 0 \\
\text { Atorvastatin } \\
80 \text { mg: } 0.9 \% \\
\text { vs. } 1.9 \%\end{array}$ \\
\hline \multicolumn{9}{|c|}{ Specific adverse events: potential injection-site reactions ${ }^{b}$} \\
\hline $\begin{array}{l}\text { Evolocumab } \\
420 \mathrm{mg} Q 4 \\
\text { weeks × } 12 \\
\text { weeks vs. } \\
\text { ezetimibe } \\
10 \mathrm{mg} \text { : } \\
\text { Insufficient }\end{array}$ & $\begin{array}{l}1 \text { RCT; Atorvastatin } \\
10 \text { mg group: evo- } \\
\text { locumab } N=110 \mathrm{vs} \text {. } \\
\text { placebo } \mathrm{N}=55 \\
\text { Atorvastatin } \\
80 \text { mg group: evo- } \\
\text { locumab } \mathrm{N}=110 \mathrm{vs} \text {. } \\
\text { ezetimibe } \mathrm{N}=54\end{array}$ & Medium & Direct & Unknown & Imprecise & Not detected & None & $\begin{array}{l}\text { No difference; Any } \\
\text { statin + any evo- } \\
\text { locumab }=1.3 \% \text { vs. } \\
\text { atorvastatin + ezeti- } \\
\text { mibe }=0.9 \% \text {; NR for } \\
\text { individual ezetimibe or } \\
\text { evolocumab groups }\end{array}$ \\
\hline
\end{tabular}




\section{APPENDIX B Strength of Evidence (continued)}

\begin{tabular}{|c|c|c|c|c|c|c|c|c|}
\hline $\begin{array}{l}\text { Strength of } \\
\text { Evidence Grade }\end{array}$ & $\begin{array}{l}\text { Study Design; } \\
\text { No. Studies (N) }\end{array}$ & $\begin{array}{l}\text { Study } \\
\text { Limitations }\end{array}$ & Directness & Consistency & Precision & $\begin{array}{l}\text { Reporting } \\
\text { Bias }\end{array}$ & Other Issues & Finding \\
\hline \multicolumn{9}{|c|}{ Key Question 4. Statin Intolerant } \\
\hline \multicolumn{9}{|c|}{$\begin{array}{l}\text { Evolocumab vs. ezetimibe over } 12 \text { weeks (GAUSS: evolocumab } 280 \mathrm{mg}, 350 \text {, or } 420 \mathrm{mg} \text { given every } 4 \text { weeks vs. ezetimibe } 10 \mathrm{mg} \text {; GAUSS-2: } \\
\text { evolocumab } 140 \mathrm{mg} \text { every two weeks or } 420 \mathrm{mg} \text { once monthly to ezetimibe } 10 \mathrm{mg} \text { ) } 17,18\end{array}$} \\
\hline LDL-C: Low & 2 RCTs, $N=434$ & Medium & Direct & Consistent & Imprecise & Undetected & None & $\begin{array}{l}\text { Higher reduction for } \\
\text { evolocumab: }-26 \% \\
\text { ( } 95 \% \text { CI, }-34.1 \% \text { to } \\
-17.9 \% \text { ) for } 280 \mathrm{mg} \\
\text { every } 4 \text { weeks in } \\
\text { GAUSS to }-38 \% \text { ( } 95 \% \\
\text { CI, }-43.7 \text { to }-32.4 \text { ) for } \\
140 \text { mg every } 2 \text { weeks } \\
\text { in GAUSS-2 }\end{array}$ \\
\hline HDL-C: Low & 2 RCTs, $N=434$ & Medium & Direct & Consistent & Imprecise & Undetected & None & $\begin{array}{l}\text { Evolocumab has a } \\
\text { similar or better \% } \\
\text { change from baseline: } \\
\text { Range }=3.6 \%(95 \% \mathrm{CI} \text {, } \\
-1.5 \text { to } 8.6) \text { to } 8.5 \% \\
(P=0.020)\end{array}$ \\
\hline $\begin{array}{l}\text { Overall AE: } \\
\text { Low }\end{array}$ & 2 RCTs, $N=434$ & Medium & Direct & Consistent & Imprecise & Undetected & None & $\begin{array}{l}63 \% \text { vs. } 69 \% \text {; RR } 0.92 \\
(95 \% \text { CI, } 0.80 \text { to } 1.06)\end{array}$ \\
\hline $\begin{array}{l}\text { AE withdrawal: } \\
\text { Low }\end{array}$ & 2 RCTs, $N=434$ & Medium & Direct & Consistent & Imprecise & Undetected & None & $\begin{array}{l}3 \% \text { vs. } 12 \% ; \text { RR } 0.29 \\
(95 \% \text { CI, } 0.14 \text { to } 0.63)\end{array}$ \\
\hline $\begin{array}{l}\text { Serious AE: } \\
\text { Low }\end{array}$ & 2 RCTs, $N=434$ & Medium & Direct & Consistent & Imprecise & Undetected & None & $\begin{array}{l}3 \% \text { vs. } 3 \% ; \text { RR } 1.04 \\
(95 \% \text { CI, } 0.34 \text { to } 3.15)\end{array}$ \\
\hline $\begin{array}{l}\text { Neurocognitive } \\
\text { dysfunction: } \\
\text { Low }\end{array}$ & 2 RCTs, $N=434$ & Medium & Direct & Consistent & Imprecise & Undetected & None & No events \\
\hline $\begin{array}{l}\text { Injection site: } \\
\text { Insufficient }\end{array}$ & $1 \mathrm{RCT}, \mathrm{N}=307$ & Medium & Direct & Unknown & Imprecise & Undetected & None & $\begin{array}{l}\text { No difference; 3\% vs. } \\
8 \%\end{array}$ \\
\hline \multicolumn{9}{|c|}{ Evolocumab $420 \mathrm{mg}$ every 4 weeks plus ezetimibe $10 \mathrm{mg}$ versus ezetimibe $10 \mathrm{mg}$ alone $\times 12$ weeks } \\
\hline LDL-C: Low & $1 \mathrm{RCT}, \mathrm{N}=62$ & Medium & Direct & Unknown & Imprecise & Undetected & None & $\begin{array}{l}\text { Greater reduction: } \\
(-47 \% ; 95 \% \text { CI, }-53.7 \% \\
\text { to }-40.8 \%)\end{array}$ \\
\hline $\begin{array}{l}\text { HDL-C: } \\
\text { Insufficient }\end{array}$ & $1 \mathrm{RCT}, \mathrm{N}=62$ & Medium & Direct & Unknown & Imprecise & Undetected & None & $\begin{array}{l}\text { Greater increase: (12\%; } \\
95 \% \text { CI, } 3.9 \text { to } 20.1)\end{array}$ \\
\hline $\begin{array}{l}\text { Overall AE: } \\
\text { Insufficient }\end{array}$ & $1 \mathrm{RCT}, \mathrm{N}=62$ & Medium & Direct & Unknown & Imprecise & Undetected & None & $67 \%$ vs. $59 \%$ \\
\hline $\begin{array}{l}\text { AE withdrawal: } \\
\text { Insufficient }\end{array}$ & $1 \mathrm{RCT}, \mathrm{N}=62$ & Medium & Direct & Unknown & Imprecise & Undetected & None & $3 \%$ vs. $6 \%$ \\
\hline $\begin{array}{l}\text { Serious AE: } \\
\text { Insufficient }\end{array}$ & $1 \mathrm{RCT}, \mathrm{N}=62$ & Medium & Direct & Unknown & Imprecise & Undetected & None & No events \\
\hline $\begin{array}{l}\text { Neurocognitive } \\
\text { dysfunction: } \\
\text { Insufficient }\end{array}$ & $1 \mathrm{RCT}, \mathrm{N}=62$ & Medium & Direct & Unknown & Imprecise & Undetected & None & NR \\
\hline $\begin{array}{l}\text { Injection site: } \\
\text { Insufficient }\end{array}$ & $1 \mathrm{RCT}, \mathrm{N}=62$ & Medium & Direct & Unknown & Imprecise & Undetected & None & NR \\
\hline \multicolumn{9}{|c|}{ Long-term evidence in mixed populations (OSLER-1 and OSLER-2)16 } \\
\hline \multicolumn{9}{|c|}{ Evolocumab $420 \mathrm{mg} \mathrm{q} 4 \mathrm{w}$ (OSLER-1) or $140 \mathrm{mg} \mathrm{q} 2 \mathrm{w}$ or $420 \mathrm{mg} \mathrm{q} 4 \mathrm{w}$ (OSLER-2) + standard therapy vs. standard therapy alone $\times 48 \mathrm{w}$} \\
\hline \multicolumn{9}{|c|}{ LDL-C lowering ability } \\
\hline $\begin{array}{l}\text { Evolocumab + } \\
\text { standard } \\
\text { therapy vs. } \\
\text { standard } \\
\text { therapy alone: } \\
\text { Moderate }\end{array}$ & $\begin{array}{l}\text { RCT: } 2 \\
(4,465)\end{array}$ & Medium & Direct & Consistent & Precise & Undetected & None & $\begin{array}{l}\text { Evolocumab reduced } \\
\text { LDL-C by } 61 \%(95 \% \\
\text { CI, } 59 \text { to } 63, P<0.001) \\
\text { at } 12 \mathrm{w} \text { and by } 58.4 \% \\
(95 \% \mathrm{CI} \text { NR, } P<0.001) \\
\text { at } 48 \mathrm{w} \text { as compared to } \\
\text { standard therapy }\end{array}$ \\
\hline
\end{tabular}




\section{APPENDIX B Strength of Evidence (continued)}

\begin{tabular}{|c|c|c|c|c|c|c|c|c|}
\hline $\begin{array}{l}\text { Strength of } \\
\text { Evidence Grade }\end{array}$ & $\begin{array}{l}\text { Study Design; } \\
\text { No. Studies (N) }\end{array}$ & $\begin{array}{c}\text { Study } \\
\text { Limitations }\end{array}$ & Directness & Consistency & Precision & $\begin{array}{l}\text { Reporting } \\
\text { Bias }\end{array}$ & Other Issues & Finding \\
\hline \multicolumn{9}{|c|}{ LDL-C lowering ability: \% patients with LDL $\leq 100$ or $\leq 70$ at 12 weeks } \\
\hline $\begin{array}{l}\text { Evolocumab+ } \\
\text { standard } \\
\text { therapy vs. } \\
\text { standard } \\
\text { therapy alone: } \\
\text { Low }\end{array}$ & $\begin{array}{l}\text { RCT: } 2 \\
(4,465)\end{array}$ & Medium & Direct & Unknown & Precise & Undetected & None & $\begin{array}{l}\text { \% patients with LDL } \\
\text { reduced to } 100 \mathrm{mg} / \\
\text { dL or lower }(90.2 \% \text { vs. } \\
26.0 \%) \text { or } 70 \mathrm{mg} / \mathrm{dL} \\
(73.6 \% \text { vs. } 3.8 \%)\end{array}$ \\
\hline \multicolumn{9}{|c|}{ HDL-C raising ability } \\
\hline $\begin{array}{l}\text { Evolocumab+ } \\
\text { standard } \\
\text { therapy vs. } \\
\text { standard } \\
\text { therapy alone: } \\
\text { Low }\end{array}$ & $\begin{array}{l}\text { RCT: } 2 \\
(4,465)\end{array}$ & Medium & Direct & Unknown & Precise & Undetected & None & $\begin{array}{l}\text { Change from baseline } \\
\text { in HDL-C at } 12 \mathrm{w} \text { was } \\
8.7 \% \text { in evolocumab } \\
\text { group vs. } 1.7 \% \text { in } \\
\text { standard therapy alone } \\
\text { group }(P<0.001)\end{array}$ \\
\hline \multicolumn{9}{|c|}{ Overall adverse events } \\
\hline $\begin{array}{l}\text { Evolocumab+ } \\
\text { standard } \\
\text { therapy vs. } \\
\text { standard } \\
\text { therapy alone: } \\
\text { Low }\end{array}$ & $\begin{array}{l}\text { RCT: } 2 \\
(4,465)\end{array}$ & Medium & Direct & Unknown & Precise & Undetected & None & $\begin{array}{l}\text { Any AEs occurred in } \\
69.2 \% \text { of evolocumab } \\
\text { group and } 64.8 \% \text { of } \\
\text { standard therapy alone } \\
\text { group }\end{array}$ \\
\hline \multicolumn{9}{|c|}{ Withdrawals due to adverse events } \\
\hline $\begin{array}{l}\text { Evolocumab } \\
\text { + standard } \\
\text { therapy vs. } \\
\text { standard } \\
\text { therapy alone: } \\
\text { Insufficient }\end{array}$ & $\begin{array}{l}\text { RCT: } 2 \\
(4,465)\end{array}$ & Medium & Direct & Unknown & Imprecise & Undetected & None & $\begin{array}{l}2.4 \% \text { of patients in } \\
\text { evolocumab group } \\
\text { prematurely discontin- } \\
\text { ued study drug due to } \\
\text { AEs (NA for standard } \\
\text { therapy group) }\end{array}$ \\
\hline \multicolumn{9}{|c|}{ Serious adverse events } \\
\hline $\begin{array}{l}\text { Evolocumab } \\
\text { + standard } \\
\text { therapy vs. } \\
\text { standard } \\
\text { therapy alone: } \\
\text { Low }\end{array}$ & $\begin{array}{l}\text { RCT: } 2 \\
(4,465)\end{array}$ & Medium & Direct & Unknown & Precise & Undetected & None & $\begin{array}{l}\text { No difference in } \% \text { of } \\
\text { patients with SAEs } \\
\text { ( } 7.5 \% \text { for both groups) }\end{array}$ \\
\hline \multicolumn{9}{|c|}{ Specific adverse events: neurocognitive events } \\
\hline $\begin{array}{l}\text { Evolocumab } \\
\text { + standard } \\
\text { therapy vs. } \\
\text { standard } \\
\text { therapy alone: } \\
\text { Insufficient }\end{array}$ & $\begin{array}{l}\text { RCT: } 2 \\
(4,465)\end{array}$ & Medium & Direct & Unknown & Imprecise & Undetected & None & $\begin{array}{l}0.9 \% \text { in evolocumab } \\
\text { group vs. } 0.3 \% \text { in stan- } \\
\text { dard therapy group }\end{array}$ \\
\hline \multicolumn{9}{|c|}{ Specific adverse events: injection-site reactions } \\
\hline $\begin{array}{l}\text { Evolocumab+ } \\
\text { standard } \\
\text { therapy vs. } \\
\text { standard } \\
\text { therapy alone: } \\
\text { Insufficient }\end{array}$ & $\begin{array}{l}\text { RCT: } 2 \\
(4,465)\end{array}$ & Medium & Direct & Unknown & Imprecise & Undetected & None & $\begin{array}{l}4.3 \% \text { of patients in } \\
\text { evolocumab group (NA } \\
\text { for standard therapy } \\
\text { group) }\end{array}$ \\
\hline \multicolumn{9}{|c|}{ Specific adverse events: gastroenteritis } \\
\hline $\begin{array}{l}\text { Evolocumab + } \\
\text { standard } \\
\text { therapy vs. } \\
\text { standard } \\
\text { therapy alone: } \\
\text { Insufficient }\end{array}$ & $\begin{array}{l}\text { RCT: } 2 \\
(4,465)\end{array}$ & Medium & Direct & Unknown & Imprecise & Undetected & None & $\begin{array}{l}1.5 \% \text { of patients in } \\
\text { evolocumab group } \\
\text { vs. } 0.8 \% \text { in standard } \\
\text { therapy group }\end{array}$ \\
\hline
\end{tabular}




\section{APPENDIX B Strength of Evidence (continued)}

\begin{tabular}{|c|c|c|c|c|c|c|c|c|}
\hline $\begin{array}{l}\text { Strength of } \\
\text { Evidence Grade }\end{array}$ & $\begin{array}{l}\text { Study Design; } \\
\text { No. Studies (N) }\end{array}$ & $\begin{array}{c}\text { Study } \\
\text { Limitations }\end{array}$ & Directness & Consistency & Precision & $\begin{array}{c}\text { Reporting } \\
\text { Bias }\end{array}$ & Other Issues & Finding \\
\hline \multicolumn{9}{|c|}{ Specific adverse events: cardiovascular events } \\
\hline $\begin{array}{l}\text { Evolocumab+ } \\
\text { standard } \\
\text { therapy vs. } \\
\text { standard } \\
\text { therapy alone: } \\
\text { Insufficient }\end{array}$ & $\begin{array}{l}\text { RCT: } 2 \\
(4,465)\end{array}$ & Medium & Direct & Unknown & Imprecise & Undetected & None & $\begin{array}{l}\mathrm{CV} \text { events at } 1 \text { year } \\
\text { reduced from } 2.18 \% \\
\text { in standard therapy } \\
\text { group vs. } 0.95 \% \text { in } \\
\text { evolocumab group (HR } \\
\text { evolocumab, } 0.47 ; 95 \% \\
\text { CI, } 0.28 \text { to } 0.78 \text { ) }\end{array}$ \\
\hline
\end{tabular}

Note: Numbered footnotes refer to citations listed in References at the end of the appendices.

ancludes deliria (including confusion), cognitive and attention disorders and disturbances, dementia and amnestic disorders, disturbances in thinking and perception, and mental impairment disorders.

bIncludes injection-site rash, inflammation, pruritus, reaction, or urticaria.

$A E=$ adverse events; $C I=$ confidence interval; $C V=$ cardiovascular; $E P C=$ Evidence-based Practice Center; $G I=$ gastrointestinal; HDL-C=high-density lipoprotein cholesterol; $H R=$ hazard ratio; $L D L-C=$ low-density lipoprotein-cholesterol; $N A=$ not available; $N R=$ not reported; $N S=$ not sufficient; $R C T=$ randomized controlled trial; $R R=$ relative risk.

\section{REFERENCES FOR APPENDICES A AND B}

1. Cannon CP, Cariou B, Blom D, et al. Efficacy and safety of alirocumab in high cardiovascular risk patients with inadequately controlled hypercholesterolaemia on maximally tolerated doses of statins: the ODYSSEY COMBO II randomized controlled trial. Eur Heart J. 2015;36(19):1186-94.

2. Kereiakes DJ, Robinson JG, Cannon CP, et al. Efficacy and safety of the proprotein convertase subtilisin/kexin type 9 inhibitor alirocumab among high cardiovascular risk patients on maximally tolerated statin therapy: the ODYSSEY COMBO I study. Am Heart J. 2015;169(6):906-15.e913.

3. McKenney JM, Koren MJ, Kereiakes DJ, Hanotin C, Ferrand A-C, Stein EA. Safety and efficacy of a monoclonal antibody to proprotein convertase subtilisin/kexin type 9 serine protease, SAR236553/REGN727, in patients with primary hypercholesterolemia receiving ongoing stable atorvastatin therapy. J Am Coll Cardiol. 2012;59(25):2344-53.

4. Robinson JG, Farnier M, Krempf M, et al. Efficacy and safety of alirocumab in reducing lipids and cardiovascular events. N Engl J Med. 2015;372(16): 1489-99.

5. Roth EM, McKenney JM, Hanotin C, Asset G, Stein EA. Atorvastatin with or without an antibody to PCSK9 in primary hypercholesterolemia. N Engl J Med. 2012;367(20):1891-900.

6. Stein EA, Gipe D, Bergeron J, et al. Effect of a monoclonal antibody to PCSK9, REGN727/SAR236553, to reduce low-density lipoprotein cholesterol in patients with heterozygous familial hypercholesterolaemia on stable statin dose with or without ezetimibe therapy: a phase 2 randomised controlled trial. Lancet. 2012;380(9836):29-36.

7. Stein EA, Mellis S, Yancopoulos GD, et al. Effect of a monoclonal antibody to PCSK9 on LDL cholesterol. N Engl J Med. 2012;366(12):1108-18.

8. Blom DJ, Hala T, Bolognese M, et al. A 52-week placebo-controlled trial of evolocumab in hyperlipidemia. N Engl J Med. 2014;370(19):1809-19.

9. Giugliano RP, Desai NR, Kohli P, et al. Efficacy, safety, and tolerability of a monoclonal antibody to proprotein convertase subtilisin/kexin type 9 in combination with a statin in patients with hypercholesterolaemia (LAPLACE-TIMI 57): a randomised, placebo-controlled, dose-ranging, phase 2 study. Lancet. 2012;380(9858):2007-17.
10. Desai NR, Giugliano RP, Zhou J, et al. AMG 145, a monoclonal antibody against PCSK9, facilitates achievement of national cholesterol education program-adult treatment panel III low-density lipoprotein cholesterol goals among high-risk patients: an analysis from the LAPLACE-TIMI 57 trial (LDL-C assessment with PCSK9 monoclonal antibody inhibition combined with statin thErapy-thrombolysis in myocardial infarction 57). J Am Coll Cardiol. 2014;63(5):430-33.

11. Hirayama A, Honarpour N, Yoshida M, et al. Effects of evolocumab (AMG 145), a monoclonal antibody to PCSK9, in hypercholesterolemic, statin-treated Japanese patients at high cardiovascular risk-primary results from the phase 2 YUKAWA study. Circ J. 2014;78(5):1073-82.

12. Raal F, Scott R, Somaratne R, et al. Low-density lipoprotein cholesterol-lowering effects of AMG 145, a monoclonal antibody to proprotein convertase subtilisin/kexin type 9 serine protease in patients with heterozygous familial hypercholesterolemia: the Reduction of LDL-C with PCSK9 Inhibition in Heterozygous Familial Hypercholesterolemia Disorder (RUTHERFORD) randomized trial. Circulation. 2012;126(20):2408-17.

13. Raal FJ, Stein EA, Dufour R, et al. PCSK9 inhibition with evolocumab (AMG 145) in heterozygous familial hypercholesterolaemia (RUTHERFORD-2): A randomised, double-blind, placebo-controlled trial. Lancet. 2015;385(9965):331-40.

14. Raal FJ, Honarpour N, Blom DJ, et al. Inhibition of PCSK9 with evolocumab in homozygous familial hypercholesterolaemia (TESLA Part B): A randomised, double-blind, placebo-controlled trial. Lancet. 2015;385(9965):341-50.

15. Robinson JG, Nedergaard BS, Rogers WJ, et al. Effect of evolocumab or ezetimibe added to moderate- or high-intensity statin therapy on LDL-C lowering in patients with hypercholesterolemia: the LAPLACE-2 randomized clinical trial. JAMA. 2014;311(18):1870-82.

16. Sabatine MS, Giugliano RP, Wiviott SD, et al. Efficacy and safety of evolocumab in reducing lipids and cardiovascular events. N Engl J Med. 2015;372(16):1500-09.

17. Stroes E, Colquhoun D, Sullivan D, et al. Anti-PCSK9 antibody effectively lowers cholesterol in patients with statin intolerance: the GAUSS-2 randomized, placebo-controlled phase 3 clinical trial of evolocumab. J Am Coll Cardiol. 2014;63(23):2541-48.

18. Sullivan D, Olsson AG, Scott R, et al. Effect of a monoclonal antibody to PCSK9 on low-density lipoprotein cholesterol levels in statin-intolerant patients: the GAUSS randomized trial. JAMA. 2012;308(23):2497-506. 